\title{
Las colecciones arqueológicas egipcias del Museo Etnográfico "Juan B. Ambrosetti": avances en su investigación
}

\section{Marina Marchegiani†, Alejandra Reynoso", Gabriela} Ammirati" y Juan M. Estevez"

En recuerdo de nuestra querida amiga y compañera Marina Marchegiani, quien siempre estará con nosotros
Recibido:

28 de abril de 2019

Aceptado:

5 de diciembre de 2019

\section{Palabras clave}

Museo Etnográfico "Juan B. Ambrosetti"

Colecciones arqueológicas egipcias

Investigación

Puesta en valor que, junto a la importancia científica de este patrimonio, llevaron a plantear un proyecto de puesta en valor a través tanto de la investigación documental, bibliográfica y hemerográfica como de la investigación de la conservación de estos materiales. Con este proyecto se busca implementar estrategias adecuadas para la preservación integral de las colecciones egipcias del Museo Etnográfico.

\section{The egyptian archaeological collections of the Ethnographic Museum "Juan B. Ambrosetti": advances in its research}

\footnotetext{
Abstract

The Ethnographic Museum “Juan B. Ambrosetti”, Facultad de Filosofía y Letras (FFyL) ("College of Philosophy and Literature"), Universidad de Buenos Aires (UBA) has Egyptian collections that came to the museum by different ways, distinguishing those that entered directly to this institution since 1911 and those that entered at the year 1947 from the Argentine Museum of Natural Sciences. Along the historical trajectory of these collections in both institutions there were modifications, deteriorations and

Keywords

Ethnographic Museum "Juan B. Ambrosetti"

Egyptian archaeological collections

Research

Valorization project 
1. Por Decreto del Poder Ejecutivo Nacional № 16211 del 10 de junio de 1947, se autorizó la transferencia de las colecciones arqueológicas, etnográficas y de antropología biológica del Museo Argentino de Ciencias Naturales a la Universidad de Buenos Aires, disponiendo su ubicación en el Museo Etnográfico de la Facultad de Filosofía y Letras (“Legajo 180 MCN”, n.d.). restorations in the objects that, together with the scientific importance that this heritage has led to propose a project of valorization through documentary, bibliographic and hemerographic research, as well as the investigation of the conservation of these materials. This project seeks to implement appropriate strategies for the integral preservation of the Egyptian collections of the Ethnographic Museum.

\section{Introducción}

El Museo Etnográfico de la Facultad de Filosofía y Letras de la Universidad de Buenos Aires fue fundado en 1904 con el objetivo de promover la investigación, enseñanza y difusión de la arqueología y etnografía, con especial énfasis en las problemáticas americanas. Juan Bautista Ambrosetti, profesor de la cátedra de Arqueología Americana de la Facultad de Filosofía y Letras, promovió la creación del mencionado Museo, que lleva su nombre desde el año 1965.

El patrimonio del Museo asciende a unos 120.000 objetos provenientes de distintas partes del mundo y se formó a través de canjes, donaciones, compras, misiones etnográficas y campañas arqueológicas organizadas por la institución en nombre de la Facultad de Filosofía y Letras. Desde épocas tempranas, el mismo Ambrosetti promocionó el canje de colecciones como una vía de obtención de objetos "exóticos" o de difícil acceso en esta parte del mundo, utilizando para la realización de este tipo de canjes, "duplicados" de piezas arqueológicas recuperadas en las distintas campañas de excavación. Por otra parte, en el año 1947 el Museo recibió a modo de traspaso una cantidad importante de colecciones arqueológicas, etnográficas y de antropología biológica de parte del Museo Argentino de Ciencias Naturales "Bernardino Rivadavia" (MACN), duplicándose así su patrimonio ${ }^{1}$.

En la actualidad, el Área de Arqueología del Museo Etnográfico custodia alrededor de 80.000 objetos de distintas partes de América, Europa, África, Asia y Oceanía, los cuales abarcan un amplio lapso temporal. Los objetivos del área son los de gestionar, preservar, organizar, investigar y comunicar al público general y especializado el acervo arqueológico de la institución. Para esto se desarrollan trabajos de investigación relacionados con la documentación e historia de las colecciones, la conservación, el estudio de la materialidad de los objetos (incluyendo aspectos tecnológicos y de deterioro), el inventario y la gestión del acervo.

\section{Colecciones egipcias e investigación asociada}

El Área de Arqueología del Museo Etnográfico cuenta con distintas colecciones de objetos procedentes de Egipto que ingresaron al museo en los años 1911, 1913, 1914, 1915, 1921, 1927, 1947 y 1967 a través de compras y donaciones (incluyendo el traspaso del MACN). Estas colecciones están conformadas por tres ataúdes de madera, dos momias de animales, estatuillas conocidas como ushebty, dos papiros, una máscara mortuoria, un fragmento de cartonaje, esculturas que representan deidades - realizadas en cerámica, metal y piedra-, artefactos líticos, sellos escarabeos, fragmentos cerámicos y calcos. Además de la diversidad de objetos y materiales que las componen, las colecciones abarcan un amplio lapso temporal, que va desde el Reino Medio (2066 a.C. - 1650 a.C.) hasta la época Romana (30 a.C. - 395 d.C.).

A lo largo de sus trayectorias históricas, estos objetos experimentaron transformaciones, pérdidas de materiales, diversos deterioros y posibles restauraciones que, junto a su importancia arqueológica, llevaron a plantear la necesidad de su puesta en valor a través 
de la investigación tanto documental como de conservación ${ }^{2}$. Para abordar este trabajo se consideraron distintas problemáticas. En primer lugar, la falta de correspondencia entre los objetos y su correlato documental, producido por la pérdida de información contextual vinculada al hallazgo, a la circulación previa al ingreso a una institución y a la vida de los objetos dentro de los museos. Esta falta de correspondencia también puede deberse a la pérdida de información asociada físicamente a las piezas, como por ejemplo segmentos iconográficos, inscripciones originales, números de inventario, rótulos. En segundo lugar, otra problemática se debe a la presencia de réplicas y falsificaciones dentro de las colecciones y la existencia de objetos con agregados o reconstrucciones parciales difíciles de diferenciar de sus partes originales.

De esta manera, para la puesta en valor de las colecciones egipcias se está desarrollando un plan integral que tiene como objetivos la indagación de las trayectorias históricas de las colecciones, la recopilación de los trabajos de investigación que se han realizado hasta el presente con estos objetos, el relevamiento actual de estas colecciones en sus lugares de guarda y del estado de conservación de las piezas, el estudio de aspectos tecnológicos, la elaboración de propuestas de tratamientos y guardas adecuadas para los objetos y la documentación y recatalogación de todas las colecciones. En este proceso, las técnicas analíticas constituyen herramientas importantes ya que aportan datos relevantes para el estudio de los materiales constitutivos y manufactura, la identificación de los deterioros presentes y el reconocimiento de materiales no originales agregados a través del tiempo y de restauraciones antiguas.

\section{Antecedentes de investigación sobre las colecciones egipcias del Museo Etnográfico}

En el año 1925, el Profesor de Egiptología del Colegio de Francia, Alexandre Moret, estudió las colecciones arqueológicas egipcias del Museo de Historia Natural de Buenos Aires, actualmente alojadas en el Museo Etnográfico. Si bien, como se mencionará más adelante, existen referencias sobre algunos de estos objetos publicados en la segunda mitad del siglo XIX, destacamos el estudio de Moret (1925) ya que quizás sea el primero que puso su atención en estas colecciones desde el marco de una disciplina científica ya afianzada. En este sentido es interesante destacar la apreciación de Moret cuando afirma que "esa colección ofrece verdadero interés, puesto que ofrece un resumen de los distintos dogmas relativos a las promesas de vida futura en los antiguos egipcios; ella podría servir de base a una futura sección arqueológica egipcia que la ciudad de Buenos Aires tiene derecho a exigir" (Moret, 1925, p. 5).

Pocas décadas después y como parte de las investigaciones fundacionales de la egiptología argentina, Perla Fuscaldo y Abraham Rosenvasser impulsaron la difusión y valoración de las colecciones egipcias del Museo Etnográfico. Así, en la década de 1970, la primera mención detallada la hace Rosenvasser en su introducción a los estudios sobre las piezas egipcias del Museo Etnográfico, que fueron publicados en varios números de la Revista del Instituto de Historia Antigua Oriental. Allí se menciona la presencia de "un ataúd muy bien conservado y restos de otros dos, una tabla funeraria con su máscara, cinco ushebti, siete estatuillas, una máscara funeraria, animales momificados y dos papiros" (Rosenvasser, 1972a, p. 4). Un aspecto fundamental de estas investigaciones es la interpretación de las inscripciones jeroglíficas. De esta manera, el análisis de la escritura del papiro "Buenos Aires" le permite ubicarlo cronológicamente entre las dinastías XII y XIII (Rosenvasser, 1972a), esto es entre el Reino Medio (2066 a.C. - 1650 a.C.) y el Segundo Período intermedio (1650 a.C. - 1550 a.C.). De la misma manera data al papiro funerario "Khonsu-Thot" en el período tardío griego (Rosenvasser, 1972b). Un abordaje similar realizó Fuscaldo, quien se abocó al estudio de las inscripciones del ataúd de Amenardis ${ }^{3}$, el cual sostiene pertenece a época tardía (Fuscaldo, 1972b). Al
2. Actualmente las actividades relacionadas a la investigación de colecciones se desarrollan dentro del proyecto ANPCyT PICT 20151394, denominado “Aplicación de técnicas analíticas como sustento de la investigación, conservación y puesta en valor de las colecciones del Museo Etnográfico “Juan B. Ambrosetti”, dirigido por la Dra. Mónica Berón. Este proyecto se propone desarrollar estrategias de preservación del patrimonio.
3. Los trabajos más recientes transcriben este nombre como Amenirdis (Bonanno, 2019; Santos, 2003, 2007). 
mismo tiempo, las piezas que no poseen inscripciones fueron estudiadas basándose en sus características estilísticas (Fuscaldo, 1973-1974a, 1978a). Estos trabajos pioneros tenían como objetivo abordar temas centrales de la egiptología, por lo que la indagación sobre la historia de las colecciones y la evaluación de su estado de conservación no fueron instancias de investigación explícitamente desarrolladas.

Los investigadores comenzaron a preguntarse por la trayectoria histórica de las colecciones egipcias del Museo Etnográfico a comienzos de este siglo, publicándose las primeras indagaciones documentales al respecto (Santos, 2003, 2007). Éstas pueden incluirse también dentro de una temática más amplia vinculada a la circulación y mercantilización de antigüedades egipcias y a los procesos de formación de este tipo de colecciones durante el siglo XIX. En este sentido, se realizaron investigaciones que abordan las colecciones egipcias del Museo Etnográfico vinculadas a la construcción del orientalismo en la Argentina durante el siglo XIX (Pistacchi, 2012). En algunos trabajos se hace referencia al estado de preservación general de las piezas estudiadas (Bonanno, 2019; Santos, 2003, 2007). Sin embargo, la cuestión del estado de conservación de estos objetos tampoco ocupa un lugar central en dichas publicaciones.

Teniendo en cuenta estos antecedentes, los integrantes del Área de Arqueología del Museo Etnográfico nos abocamos a la investigación documental para ampliar, profundizar y sistematizar la información recuperada con el objetivo de reconstruir la biografía de las colecciones egipcias. Al mismo tiempo, nos propusimos indagar sobre el estado de conservación de los objetos con el fin de elaborar diagnósticos que nos permitan implementar un plan adecuado para la preservación de este patrimonio.

\section{Relevamiento de las colecciones}

El criterio de organización e investigación del patrimonio del Área de Arqueología del Museo Etnográfico se basa en considerar como unidad de análisis a la colección, en tanto conjunto material definido por su fecha de ingreso y forma de adquisición. Esta perspectiva pone énfasis en el concepto de contexto, a partir del cual la información y el significado de un objeto se definen en relación con los otros componentes del conjunto del cual forma parte. Además, las colecciones no constituyen entidades estáticas; por el contrario, son conjuntos dinámicos en constante transformación, resultado del entrecruzamiento de las biografías de los objetos que las van conformando. A su vez, estas colecciones están constituidas no sólo por los objetos, sino también por su historia y significados socioculturales. Se intenta así un acercamiento antropológico al contexto socio-histórico a partir del cual un conjunto de objetos se constituye como colección en constante transformación, atravesando la historia de las instituciones y de las disciplinas científicas vinculadas. Este abordaje integral de las colecciones se ha puesto en práctica desde el año 2000 (Ammirati, Coll Moritan y Manuale, 2008; Ammirati, Coll Moritan, Reynoso y Manuale, 2010; Ammirati, Estevez, Marchegiani y Reynoso, 2018; Marchegiani, Reynoso, Ammirati y Estevez, 2018; Reynoso y Ammirati, 2013).

\section{Fuentes documentales consultadas}

El Área de Arqueología cuenta con distintas colecciones procedentes de Egipto, pudiéndose distinguir dos grandes grupos. En primer lugar, las colecciones que ingresaron directamente al Museo Etnográfico por distintas donaciones y compras en los años 1911, 1913, 1914, 1915, 1921, 1927 y 1967. Por otro lado, se encuentra el conjunto de colecciones egipcias procedentes del MACN, traspasadas en 1947. Este patrimonio ingresó originalmente al MACN también por donaciones y compras en los años 1842 (?), 1843 (?), 1848 (?), 1872 (ingresada en Catálogo de 1935), 1894, 1896, 1904 y 1905. Se destaca así, que estas piezas se conforman como colecciones museológicas 
más tempranamente que las del Museo Etnográfico, hecho que, en principio, estaría dado por la mayor antigüedad del MACN. Sin embargo, esto no explica por qué la fecha más tardía para los ingresos de objetos procedentes de Egipto a esta institución bicentenaria es el año 1905. Resulta llamativo que esta fecha sea cercana a la creación del Museo Etnográfico en 1904, observándose en consecuencia que los períodos de ingreso de colecciones egipcias a ambos museos no se superponen: fines de la primera $\mathrm{mitad} /$ segunda mitad del siglo XIX para el MACN y primera mitad/principios de la segunda mitad del siglo XX para el Museo Etnográfico. Si bien por el momento no podemos explicar esta observación, creemos que es interesante para avanzar en el estudio de la conformación y circulación de estas colecciones. Cabe preguntarse, por ejemplo, si una vez fundado el Museo Etnográfico fue el que primó en la competencia por la obtención de este tipo de colecciones o si fue el MACN el que pierde interés en las mismas. Por otro lado, es importante también indagar las trayectorias de estos objetos en el ámbito privado, es decir, con anterioridad al ingreso a los dos museos, para conocer la profundidad temporal de la circulación de estas colecciones.

A la hora de avanzar en la reconstrucción de las trayectorias históricas, las colecciones provenientes del MACN nos presentan un doble desafío de indagación documental: investigar sus biografías dentro del Museo Etnográfico y también en la institución de la cual provienen. Si bien se supone que estas colecciones fueron traspasadas con su documentación asociada (por ejemplo, los catálogos) existen vacíos de información y en la mayoría de los casos escasa documentación contextual. Por este motivo se recurrió al Archivo Fotográfico y Documental del Museo Etnográfico "Juan B. Ambrosetti" (AMEJBA), al Archivo General de la Facultad de Filosofía y Letras, Universidad de Buenos Aires (AGFFyL), al Archivo Histórico de la Universidad de Buenos Aires "Presbítero Antonio Sáenz" (AH-UBA), al Archivo Histórico del Museo Argentino de Ciencias Naturales "Bernardino Rivadavia" (AHMACN) y a la Biblioteca Prebisch del Banco Central de la República Argentina, para revisar catálogos, documentos diversos y artículos de prensa con el fin de contextualizar distintos aspectos de la formación de estas colecciones.

A partir del relevamiento de los catálogos existentes en el Museo Etnográfico - los propios de este Museo y los provenientes del MACN_, se pudo determinar que la cantidad de números de inventario correspondientes a materiales arqueológicos egipcios son 200. Este número no se corresponde exactamente con la misma cantidad de ítems, ya que hay tres números de inventario que están formados por lotes, dos de ellos de cantidad no especificada en la descripción que consta en los catálogos. Además, hay que tener en cuenta que, de los 200 números de inventario mencionados, 167 están consignados como calcos o reproducciones. En las Tablas 1 y 2 se detallan las cantidades según información de catálogos y en base al relevamiento actual de estas colecciones en sus lugares de guarda.

De este trabajo de relevamiento, que aún sigue en proceso, surge que hasta el momento el Museo cuenta con 46 ítems arqueológicos egipcios, de los cuales 31 poseen número de inventario que permite vincularlos a una colección específica, mientras que 15 se mantienen en el grupo de Colecciones indeterminadas (Tabla 2).

Es importante mencionar que gran parte de este material fue reinventariado en la base digital del Museo Etnográfico en el año 2004, gracias a la información elaborada por Diego Santos junto con Belén Daizo.

\section{Colecciones egipcias que ingresaron al Museo Etnográfico}

En la Tabla 3 se presenta la síntesis de las distintas colecciones egipcias que ingresaron directamente al Museo Etnográfico. A continuación se detallan estas colecciones siguiendo un orden cronológico. 


\begin{tabular}{|l|c|c|c|}
\hline Colecciones egipcias & $\begin{array}{c}\text { Cantidad de Números de } \\
\text { Inventario según Catálogos }\end{array}$ & $\begin{array}{c}\text { Cantidad de Números de } \\
\text { Inventario ubicados }\end{array}$ & $\begin{array}{c}\text { Cantidad de Ítems con Número } \\
\text { de Inventario ubicados }\end{array}$ \\
\hline Objetos & $33^{1}$ & $22^{3}$ & 30 \\
Calcos / Reproducciones & $167^{2}$ & 1 & 1 \\
\hline Total & 200 & 23 & 31 \\
\hline
\end{tabular}

Tabla 1. Colecciones egipcias del Museo Etnográfico. Detalle de cantidad de Números de Inventario, según información de Catálogos y en base al relevamiento. Referencias: 1) incluye lote de objetos de cantidad indeterminada y un lote de 2 objetos; 2) inlcuye un lote de objetos de cantidad indeterminada; 3 ) inlcuye un lote de 9 objetos.

4. La Donación del Ministerio de Instrucción Pública del año 1911 comprendía 642 objetos, incluyendo calcos de esculturas y relieves del Próximo Oriente Antiguo y también objetos etnográficos de distintas procedencias. Por su parte, la Donación de 1913, constó de 158 piezas, también calcos y objetos etnográficos.

\begin{tabular}{|l|c|}
\hline Colecciones egipcias & Cantidad de Ítems ubicados \\
\hline Ítems con Número de Inventario & 31 \\
Ítems de Colecciones indeterminadas & 15 \\
\hline Total & 46 \\
\hline
\end{tabular}

Tabla 2. Colecciones egipcias del Museo Etnográfico. Detalle de cantidad de ítems ubicados a partir del relevamiento.

\section{Donaciones Ministerio de Instrucción Pública (1911 y 1913)}

En 1911 y 1913 por Donación del Ministerio de Instrucción Pública, ingresan al patrimonio del museo 163 calcos de esculturas y relieves procedentes de distintos sitios de Egipto 4 . Estos materiales en la actualidad no se encuentran en el Museo Etnográfico, ya que a fines de 1934 debido a remodelaciones a realizarse en el edificio, el Director del Museo, Dr. Félix Outes, solicitó al Decano de la Facultad de Filosofía y Letras autorice la cesión en calidad de préstamo a la Dirección Nacional de Bellas Artes de más de doscientos calcos de obras escultóricas entre los que se hallaban los egipcios. Este préstamo temporario fue autorizado y se efectivizó en enero de 1935 (Outes, 1934, 1935).

\section{Donación Héctor Ambrosetti (1914)}

En 1914, por donación de Héctor Ambrosetti ingresa un conjunto de 14 objetos procedentes de Asuán (números de inventarios 18.246 a 18.259). Se trata de diez fragmentos cerámicos, dos "percutores de piedra", un "Poushapti (fig de barro)" y un "Oushapti (fig de barro)" según se detalla en el catálogo. Hasta el momento han sido ubicados los fragmentos cerámicos correspondientes a distintos estilos (Figura 1A) y los instrumentos líticos.

\section{Compra (1914)}

También en el año 1914, consta en catálogo el ingreso por compra de un "Ídolo de bronce" procedente de Egipto al que se le asignó el número de inventario 18.261, que no se ha logrado identificar hasta ahora. Ingresa también, como parte de esta adquisición y con la misma procedencia, un "Puñal de bronce" que forma parte de las colecciones etnográficas del Museo.

\section{Donación Félix Outes (1915)}

En 1915, ingresa por donación de Félix Outes, el calco de un sahumador antropomorfo. Según la información consignada en el catálogo, el original estaba depositado en el Museo de El Cairo. Este objeto, No 19.159, tampoco ha sido hallado. 


\begin{tabular}{|c|c|c|c|c|c|c|}
\hline & Año & Forma de ingreso & $\begin{array}{l}\text { Cantidad de } \\
\text { Números de } \\
\text { Inventario según } \\
\text { Catálogos }\end{array}$ & $\begin{array}{l}\text { Cantidad de } \\
\text { Números de } \\
\text { Inventario } \\
\text { ubicados }\end{array}$ & $\begin{array}{c}\text { Cantidad de Ítems } \\
\text { con Número } \\
\text { de Inventario } \\
\text { ubicados }\end{array}$ & $\begin{array}{l}\text { Tipos de Ítems con } \\
\text { Número de Inventario } \\
\text { ubicados }\end{array}$ \\
\hline \multirow{9}{*}{ 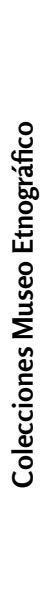 } & 1911 & $\begin{array}{l}\text { Donación Ministerio de } \\
\text { Instrucción Pública }\end{array}$ & 154 & - & - & - \\
\hline & 1913 & $\begin{array}{l}\text { Donación Ministerio de } \\
\text { Instrucción Pública }\end{array}$ & 9 & - & - & - \\
\hline & 1914 & Donación Héctor Ambrosetti & 14 & 12 & 12 & $\begin{array}{l}\text { Fragmentos cerámicos, } \\
\text { instrumentos líticos }\end{array}$ \\
\hline & 1914 & Compra & 1 & - & - & - \\
\hline & 1915 & Donación Félix Outes & 1 & - & - & - \\
\hline & 1921 & $\begin{array}{l}\text { Donación Salvador } \\
\text { Debenedetti }\end{array}$ & 2 & - & - & - \\
\hline & 1927 & Donación T. A. Le Bretón & 1 & - & - & - \\
\hline & 1967 & $\begin{array}{l}\text { Donación Suc. Martín Doello } \\
\text { Jurado }\end{array}$ & 2 & 1 & 1 & Calco \\
\hline & & Total & 184 & 13 & 13 & - \\
\hline \multirow{11}{*}{ 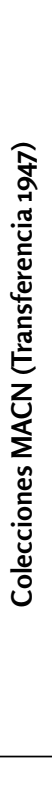 } & 1842 (?) & Juan Manuel de Rosas (?) & 1 & 1 & 1 & Ataúd de madera \\
\hline & $1843(?)$ & Tomás Gowland (?) & 1 & 1 & 1 & Escultura de piedra \\
\hline & 1848 (?) & Thomas Thondicke (?) & 3 & 2 & 2 & Ataúdes de madera \\
\hline & 1880 & $\begin{array}{l}\text { Donación Gregoria Ezcurra } \\
\text { de Cálvari }\end{array}$ & 1 & - & - & - \\
\hline & 1894 & Schliemann & 1 & 1 & 1 & $\begin{array}{l}\text { Conjunto de fragmentos } \\
\text { líticos }\end{array}$ \\
\hline & 1896 & $\begin{array}{l}\text { Donación Delfina S. de } \\
\text { Viglione }\end{array}$ & $3^{1}$ & 1 & 9 & $\begin{array}{l}\text { Papiros, momias de } \\
\text { animales, estatuillas } \\
\text { de distintos materiales, } \\
\text { fragmento de cartonaje }\end{array}$ \\
\hline & 1904 & Compra a Gastans Jaliorca (?) & $1^{2}$ & - & - & - \\
\hline & 1905 & $\begin{array}{l}\text { Donación Alejandro Marini (o } \\
\text { Marissi) }\end{array}$ & 1 & - & - & - \\
\hline & $\begin{array}{c}1872 \\
(1935)\end{array}$ & Colecciones Antiguas & 4 & 4 & 4 & $\begin{array}{l}\text { Estatuillas de distintos } \\
\text { materiales, objeto de } \\
\text { metal con figura }\end{array}$ \\
\hline & & Total & 16 & 10 & 18 & - \\
\hline & & Total general & 200 & 23 & 31 & - \\
\hline
\end{tabular}

Tabla 3. Detalle de cantidad de Números de Inventario de las distintas colecciones egipcias del Museo Etnográfico, según información de Catálogos y en base al relevamiento. Se presenta también la cantidad de ítems ubicados a partir del relevamiento y el tipo de objeto. Referencias: 1) incluye dos lotes de objetos de cantidad indeterminada; 2) un lote de 2 objetos.

\section{Donación Salvador Debenedetti (1921)}

En 1921, ingresan por donación de Salvador Debenedetti, por entonces Director del Museo, dos "Estatuas antropomorfas con jeroglíficos" (№ 27.757 y 27.758). Las mismas no han sido ubicadas.

\section{Donación T. A. Le Bretón (1927)}

En 1927, por donación del Dr. T. A. Le Breton, consta en el catálogo el ingreso de una "Porción de la pasta que rellenaba el féretro de Tutankamon" ( $\mathrm{N}^{\circ} 33.741$ ). Según las observaciones consignadas en dicho libro, este material fue entregado al Dr. Le Breton por Mr. Carter en febrero de 1926. Es interesante destacar que esta muestra fue 
A
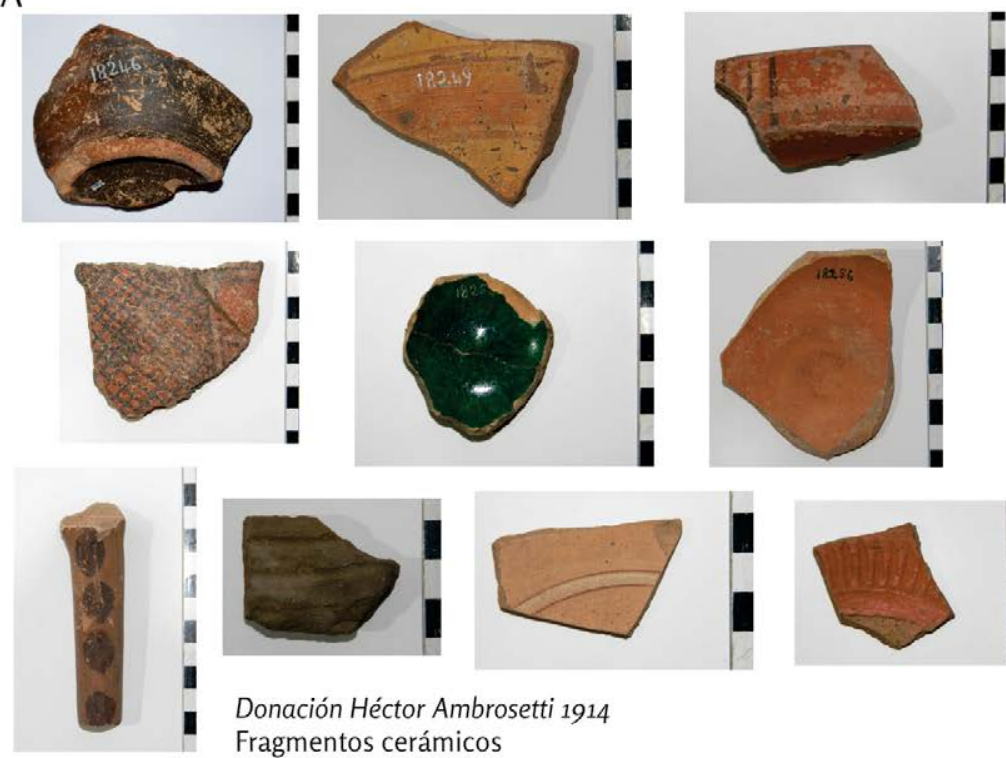$$
\text { F }
$$
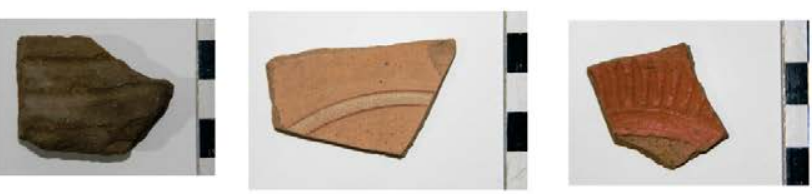

Donación Héctor Ambrosetti 1914

Fragmentos cerámicos
B

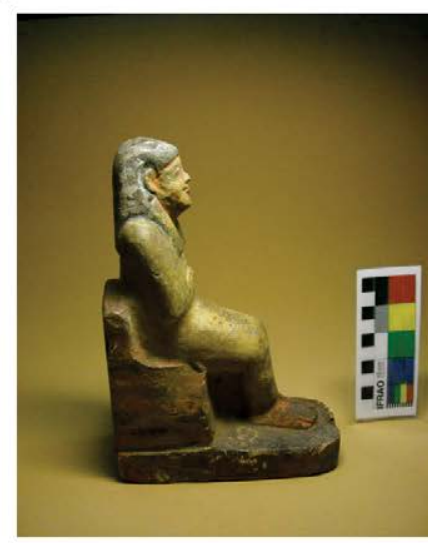

Ingreso 1843 (?)

Figura 1. A. Fragmentos cerámicos que forman parte de la Donación Héctor Ambrosetti (1914). B. Estatuilla de piedra correspondiente al Ingreso 1843 (?).

mencionada en 1927 por Salvador Debenedetti en su discurso inaugural de la nueva sede del Museo Etnográfico, sita en Moreno 350 (la cual ocupa hasta la actualidad). Allí, el Director del Museo destaca: "La última pieza, ingresada ayer, traída desde el valle de los reyes por el Dr. Tomas Le Bretón, es un fragmento de resina perfumada que el ilustre arqueólogo Carter extrajo del féretro de Tutankamon" (Pistacchi, 2012, p. 56).

\section{Donación Sucesión Martín Doello Jurado (1967)}

Finalmente, las últimas piezas arqueológicas egipcias forman parte de la Donación Sucesión del Dr. Martín Doello Jurado, ingresada en el catálogo del Museo Etnográfico del año 1967. Según la información del libro de inventario, esta colección consta de 89 objetos, principalmente piezas cerámicas. La mayoría de los materiales son griegos y greco-romanos. Sólo dos fueron consignados como egipcios: un "perfumero de cerámica" y un "calco en yeso". Esta última pieza se encuentra ubicada.

\section{Colecciones egipcias provenientes del Museo Argentino de Ciencias Naturales}

La trayectoria previa de las colecciones en el MACN imprime una marcada complejidad en su estudio. Distintos aspectos de la extensa historia de este museo son abordados por numerosos trabajos (por ejemplo, Asúa, 2012; Castello, 2014; Perazzi, 2008; Podgorny, 2009; Podgorny y Lopes, 2008). Hasta el año 1947, esta institución, fundada por Bernardino Rivadavia mediante decreto del año 1823, fue denominada sucesivamente como Sala de Física y Química y de la Conservación de los Objetos de la Historia Natural, Museo de Historia Natural, Museo Público de Buenos Aires, Museo Nacional de Buenos Aires, Museo Nacional de Historia Natural de Buenos Aires, Museo Nacional de Historia Natural "Bernardino Rivadavia" y, finalmente, Museo Argentino de Ciencias Naturales "Bernardino Rivadavia" (Castello, 2014). Esta sucesión de denominaciones refleja las cambiantes coyunturas institucionales, gubernamentales y políticas, observándose que, por ejemplo, desde 1833 a 1864 el Museo dependió de 
la Universidad de Buenos Aires; posteriormente pasó a depender directamente de la Provincia de Buenos Aires, hasta que en 1884 a raíz de la federalización de la ciudad de Buenos Aires y la nacionalización del Museo, éste se vinculó con el Ministerio de Justicia e Instrucción Pública de la Nación (Asúa, 2012; Castello, 2014). Por su parte, los diversos traslados edilicios no constituyen hitos menores a la hora de reconstruir las trayectorias históricas de las colecciones traspasadas al Museo Etnográfico. Desde su fundación y hasta 1857 el Museo funcionaba en el Convento de Santo Domingo. En dicho año se traslada al edificio de la Universidad de Buenos Aires emplazado en la Manzana de las Luces. En 1913, gran parte de sus colecciones pasan a alojarse en una nueva sede en la calle Bernardo de Irigoyen. Finalmente, entre 1927 y 1939 se realizan los traslados para ocupar el nuevo edificio construido en el Parque Centenario (Asúa, 2012), emplazamiento actual del museo.

En la Tabla 3 se presenta la síntesis de las distintas colecciones egipcias provenientes del MACN que ingresan al Museo Etnográfico como parte de la transferencia del año 1947. A continuación se detallan estas colecciones según orden cronológico.

\section{Ingreso $1842(?)$}

En el Inventario de 1842-1849 del Archivo Histórico del MACN, titulado "Registro de los efectos que han sido donados al Museo de Historia Natural de Buenos Aires; y de los que fueron introducidos en el mismo Museo por orden de Autoridades Superiores" (Castello, 2014, p. 18), se registra el ingreso del objeto $N^{o} 1$ el día 15 de noviembre de 1842: "Por orden verbal del Exmo Señor Gobernador de la Provincia Brigadier $\mathrm{D}^{\mathrm{n}}$ Juan Manuel de Rosas se ha entregado en este establecimiento un Cajón conteniendo una Mumia (el cadáver de una Muger) (sic)" (Castello, 2014, p. 18); por ende, este ataúd sería la primera pieza egipcia introducida en el antiguo MACN. El dato se complementa con la información ya aportada por Santos, relacionada con dos documentos del Museo de Historia Natural fechados el 29 y 30 de noviembre de 1842, que dan cuenta de un gasto realizado por Antonio Demarchi ${ }^{5}$ para una "Compostura al Cajón de la Mumia" (Santos 2007, pp. 49-50).

Esta momia con su ataúd sería la misma que se consigna en el "Inventario de las existencias en el Museo de Buenos Ayres, hecho por el infraescripto encargado de dicho Museo [Antonio Demarchi] el dia 22 de Febrero de 1850..., el cual da inicio al Libro de Inventario 1850-1891 del Museo Público (Inventario del Museo Argentino de Ciencias Naturales, 1850-1891, ortografía original) ${ }^{6}$. En la sección "Hystoria Natural" se menciona "1 Mumia de Egipto (el cadáver de una muger)" (Inventario del Museo Argentino de Ciencias Naturales, 1850-1891, folio 4, ortografía original).

En principio, la incorporación del antiguo documento "Registro de los efectos que han sido donados...” de 1842-1849, daría sustento a la tradición oral que vinculaba uno de los ataúdes a la figura del Gobernador Juan Manuel de Rosas. Esta posibilidad ya había sido propuesta por Santos (2007) a partir de los documentos vinculados a la reparación del ataúd realizada por Demarchi en 1842. Queda pendiente aún la constatación documental vinculada al origen de este ataúd y su momia. Quizás debería retomarse la posibilidad de que efectivamente se trate de un obsequio al gobernador de la Confederación enviado por el gobierno francés (Santos, 2003), aunque también, como veremos más adelante, existe otra versión que afirma que la entrega la habría realizado "un súbdito inglés" (Municipalidad de la Ciudad de Buenos Aires, 1954, p. 22; ver Nota 13).

En la Memoria para la Sesión Anual de la Asociación de Amigos de la Historia Natural del Plata ${ }^{7}$, publicada en 1856 por quien fuera su Secretario, Manuel Ricardo Trelles, se
5. Antonio Demarchi fue Encargado del Museo de Historia Natural entre 1842 y 1853 (Castello, 2014, p. 8).

6. En el Museo Etnográfico contamos con un extracto de este catálogo transcripto por Eric Boman, Encargado de la Sección de Arqueología del MACN entre 1917 y 1924. Fue muy importante poder acceder al libro original depositado en el AHMACN, ya que permitió cotejar ambos documentos y constatar omisiones en la transcripción (ver Nota 11).

7. La Asociación de Amigos de la Historia Natural del Plata fue creada en 1854 para la promoción y organización del Museo Público de Buenos Aires. 
8. Tanto el ataúd con su momia y la estatua, se vuelven a incluir en el inventario del 28 de marzo de 1854 (Inventario del Museo Argentino de Ciencias Naturales, 1850-1891, folios 15 y 17). menciona la existencia en el Museo Público de una momia de Egipto y su caja "cubierta de inscripciones y jeroglíficos" (Trelles, 1856, p. 9). Es muy probable que esta momia corresponda a la que ingresa en 1842.

\section{Ingreso 1843 (?)}

El segundo objeto procedente de Egipto habría ingresado al Museo de Historia Natural de Buenos Aires en 1843. Se trata de una "estatua egipcia" según consta en el mencionado Inventario de 1842-1849, aunque no pudimos acceder aún a este documento. Esta pieza se consigna también en el Inventario del 22 de febrero de 1850; efectivamente, en la sección "Trofeos y Otros Artículos" se menciona "1 Estatua de barro Egipciaca, pequeña, sentada" (Inventario del Museo Argentino de Ciencias Naturales, 1850-1891, folios 6-7, ortografía original) ${ }^{8}$.

Según el informe de Trelles, la "estatua egipciaca" fue "presentada al Museo en 1843 por D. Tomás Gowland, hoy socio de número" (Trelles, 1856, p. 24).

Esta pieza se encuentra ubicada, aunque no posee numeración original (Figura 1B). Se trata de una estatuilla realizada en piedra "que representa a una mujer sentada con las manos cruzadas sobre el pecho" (Fuscaldo, 1973-1974a, p. 157, lámina VII). Fuscaldo sitúa su producción probablemente en la dinastía XVIII; en concordancia, Santos la vincula al Reino Nuevo, aunque con algunas dudas (Fuscaldo, 1973-1974a; Santos, 2003).

\section{Ingreso 1848 (?)}

Según varias fuentes publicadas, en el año 1848 habrían ingresado al Museo de Historia Natural tres ataúdes egipcios con sus momias (Carranza, 1865; Fontana, 1870). Los mismos habrían sido donados por el comerciante norteamericano, Thomas Thondicke, "quien las compró en París a un comerciante que las había recibido de las llanuras de Saccara, cerca de la antigua Mentis" (Fontana, 1870, p. 512).

Como se observa en esta cita, el trabajo que publica Luis Fontana (1870) sobre las momias egipcias del Museo Público de Buenos Aires, constituye una fuente sumamente interesante ya que ofrece información sobre su procedencia y características de sus respectivos ataúdes. Según la descripción brindada, se trataría de un ataúd femenino y dos masculinos.

Hasta el momento no se conoce ningún libro de inventario o documento en donde se hayan consignado los datos de ingreso de estos ataúdes. A partir de la documentación vinculada, surgen dos principales problemáticas de indagación en torno a los ataúdes del Museo Público, las cuales fueron abordadas por investigaciones previas (Santos, 2003, 2007). Nuestro trabajo intenta aportar nuevos elementos para esta discusión. En primer lugar, en torno al problema de la determinación del número de ataúdes que ingresaron efectivamente a la antigua institución y sus datos de ingreso. En segundo lugar, sobre la vinculación de las piezas que actualmente se conservan en el Museo Etnográfico con las dos colecciones de ataúdes hasta el momento identificadas (la de 1842 y la de 1848). Esta última problemática se desarrollará en otra sección del presente trabajo.

En relación con el interrogante sobre la cantidad de ataúdes ingresados, existe documentación que permite sostener que los ataúdes que habrían formado parte del patrimonio del antiguo Museo Público serían cuatro. Según lo expuesto hasta ahora, en 1842 ingresa el primer ataúd y en 1848 los otros tres. Resulta llamativo, como ya 
se mencionó, que el ingreso de 1848 no se encuentre consignado (al menos hasta el momento) en ningún inventario o documentación institucional. Según la transcripción que publica Castello (2014, p. 18) de las piezas que figuran en el "Registro de los efectos que han sido donados al Museo de Historia Natural de Buenos Aires...1842-1849", no están incluidos los tres ataúdes de 1848. Tampoco están incluidos en el Libro de Inventario de 1850-1891 (AHMACN). Es más, en el listado confeccionado el 28 de marzo de 1854 (ver Nota 8), se sigue consignando la existencia de una única "Mumia de Egipto" (Inventario del Museo Argentino de Ciencias Naturales, 1850-1891, folio 15). A su vez, no se halló en el Archivo Histórico del MACN ninguna documentación vinculada a las piezas de 1848 en el lapso temporal revisado hasta el momento (1833 hasta 1892). De hecho, en la memoria oficial de mediados del siglo XIX de este Museo se sigue mencionando un solo ataúd (Trelles, 1856). Otro dato llamativo es que las fuentes más tempranas pero posteriores a 1850, esto es, Burmeister (1864), Carranza (1865) y Fontana (1870), sólo mencionan los tres ataúdes donados por Thondicke. Esta imprecisión de las fuentes también es destacada por Santos (2007). Teniendo en cuenta que las mismas fueron escritas por personas que formaban parte del Museo Público, esta imprecisión resulta aún más llamativa. Por ejemplo, como ya se mencionó, Trelles era Secretario de la Asociación de Amigos de la Historia Natural del Plata, Burmeister fue Director del Museo entre 1862 y 1892, mientras que Fontana fue su Preparador. Estas inconsistencias podrían ser indicio de causas no explicitadas, que hicieron, por un lado, que los ataúdes de 1848 no se consignaran en los registros del museo ni en la memoria oficial publicada ocho años después (Trelles, 1856) y, por otro lado, que el ataúd de 1842 no fuera incluido en las menciones de las décadas de 1860-70 (Burmeister, 1864; Carranza, 1865; Fontana, 1870). Otra explicación podría ser el simple desconocimiento y/o falta de control en el registro de las colecciones. En este sentido, habría que evaluar la incidencia del traslado del museo en 1857 a su nueva sede en la Manzana de las Luces.

Fue recién en 1925, a partir del estudio realizado por Moret, que se hace referencia a la existencia de cuatro ataúdes en el Museo de Historia Natural de Buenos Aires. Para dar detalle de esto se cuenta con dos documentos: la nota publicada por Moret en el diario La Nación del 27 de septiembre de 1925 y el informe de Héctor Greslebin, por entonces Encargado de la Sección Arqueología, en donde presenta las conclusiones más salientes del estudio de los ataúdes realizado por el investigador francés. Allí se menciona la existencia de cuatro ataúdes, dos femeninos y dos masculinos (Libro Copiador del Museo Argentino de Ciencias Naturales, 1925-1928, folio 24).

Ahora bien, actualmente en el Museo Etnográfico se conservan tres ataúdes de madera, con integridad y estados de conservación variables, que no poseen numeraciones originales. Se trata de un ataúd correspondiente a un individuo masculino y dos sarcófagos de mujeres. Es decir que el cuarto, probablemente masculino, no se habría conservado hasta nuestros días ${ }^{9}$. Esta misma cantidad, es decir tres, ya es consignada también a comienzos de la década de 1970 en la introducción de Rosenvasser (1972a). Esto nos lleva al segundo problema que desarrollaremos más adelante: identificar cuál sería la pieza ingresada en 1842 (vinculada a Rosas) y cuáles serían las correspondientes a la donación realizada por Thondicke en 1848 (procedentes de Saqqarah).

Uno de los ataúdes de mujer que se conservan en el Museo Etnográfico es quizás la pieza egipcia más conocida de esta institución ( $\mathrm{N}^{\circ}$-28.104-) (Figura 2A). Se trata de un sarcófago interno antropomorfo, bivalvo y con pedestal (Bonanno, 2019). Su tapa permanece armada y su caja fragmentada. Pertenece a una mujer llamada Amenirdis y se ubica, según propuestas recientes, en la dinastía XXVI (Bonanno, 2019; Santos, 2003, 2007). Como se mencionó anteriormente, el mismo fue estudiado por el egiptólogo francés Alexandre Moret en 1925, quien describe los distintos episodios que "forman la decoración del ataúd de Ameneritis" y repasa las fórmulas funerarias desarrolladas en las inscripciones jeroglíficas (Moret, 1925, p. 5). Según el informe de Greslebin,
9. Santos (2007) plantea la posibilidad de que la máscara funeraria conservada en el Museo Etnográfico corresponda al cuarto ataúd. 
A

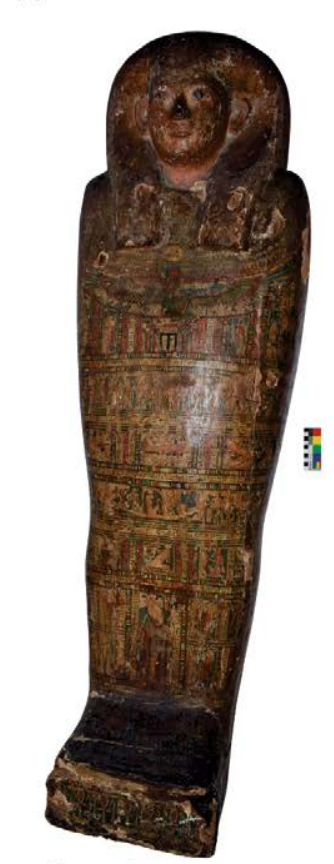

Tapa externa

Ataúd de Amenirdis (№ -28104-)
B

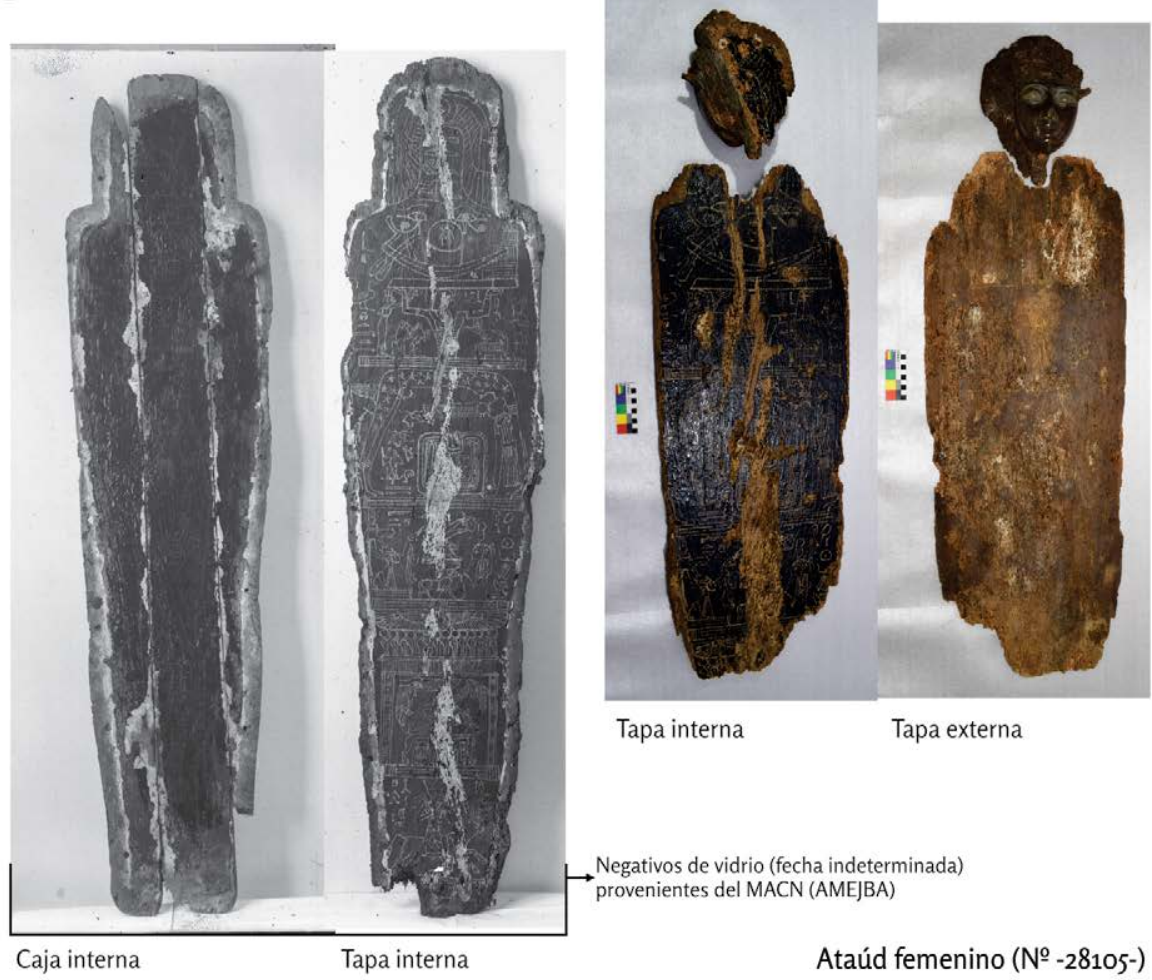

Figura 2. A. Tapa del ataúd de Amenirdis (№ -28.104-). B. Ataúd femenino (№ -28.105-). Caja y tapa internas según fotografías en negativos de vidrio de fecha indeterminada, provenientes del MACN (AMEJBA) y fotografías actuales de la tapa (cara interna y externa).

10. Para corroborar los datos de los ingresos de 1842 y 1843 esperamos tener acceso directo al documento mencionado "Registro de los efectos que han sido donados al Museo de Historia Natural de Buenos Aires...1842-1849" (Castello, 2014, p. 18). Por otra parte, el presunto ingreso de tres ataúdes en 1848 traídos por el comerciante Thomas Thondicke, no estaría consignado en ningún inventario del Museo Público, por lo que sería necesario otros sustentos documentales para corroborar esta información. el investigador francés ubica este ataúd en la dinastía XXV. Como ya se refirió, en la década de 1970 Perla Fuscaldo (1972b) publica su investigación sobre este ataúd. Los últimos aportes fueron realizados por Santos $(2003,2007)$ y Bonanno $(2019)$.

El otro ataúd femenino ( $\mathrm{N}^{\circ}$-28.105-) preserva su caja aún armada y su tapa incompleta y fragmentada. Fue también estudiado por Fuscaldo (1973-1974b, 1978b), aunque como detalla Santos (2007), erróneamente su tapa fue propuesta como tabla funeraria del ataúd de Amenirdis, mientras que su caja fue vinculada al ataúd masculino. Existen negativos de vidrio (fecha indeterminada) traspasados desde el antiguo MACN al Museo Etnográfico (AMEJBA) donde se aprecia en mejor estado de integridad, el interior de la caja y de la tapa del ataúd No -28.105- (Figura 2B).

Finalmente, el ataúd masculino ( $\mathrm{N}^{\circ}$-28.106-), del cual se conserva su tapa incompleta pero aún armada y su caja fragmentada, también fue publicado por Fuscaldo (19731974b), aunque sólo su tapa y se vincularía a la dinastía XXII (Santos, 2007).

Cabe aclarar, antes de pasar a la siguiente colección, que las fechas y los datos de adquisición de los tres primeros ingresos de piezas egipcias al antiguo MACN, es decir el ataúd (y momia) de 1842, la estatuilla de 1843 y los tres ataúdes (y momias) de 1848, se seguirán considerando dudosas hasta lograr un mayor sustento documenta ${ }^{10}$.

\section{Donación Gregoria Ezcurra de Cálvari (1880)}

En el Inventario 1850-1891 del MACN se encuentra consignado, con fecha 14 de enero de 1880, el ingreso de la colección donada por Gregoria Ezcurra de Cálvari (Inventario 
del Museo Argentino de Ciencias Naturales, 1850-1891, folio 81) ${ }^{11}$. Este conjunto incluía una "miniatura de una momia egipciaca" (junto con una lámpara etrusca, una griega y otra de Pompeya). Si bien la "miniatura" egipcia no fue identificada hasta el momento, es muy probable que se trate de un ushebty.

\section{Schliemann (1894)}

Según un extracto del segundo libro de inventario del antiguo MACN, el 28 de diciembre de 1894 ingresa al museo "Un trozo calcáreo con Nummulitas de la pirámide Kheops, Egipto" vinculado al nombre "D. J. H. Schliemann” (No 1.894/434). Como parte de esta misma colección también figuran varios objetos de Troya. En la actualidad se conservan en el Museo Etnográfico un conjunto de pequeños fragmentos líticos asociados a un rótulo original con la inscripción "Calcáreo numulítico de la pyramide de Kheops, Egipto. Sr. D. Jorge Ruscheweyh”.

Si bien Santos (2003) afirma que Ruscheweyh sería el donante de esta colección, quien a su vez la habría comprado a Schliemann, las fuentes disponibles hasta el momento no permiten precisar si se trata de una compra o de una donación y tampoco cuáles habrían sido los roles de Schliemann y Ruscheweyh. Aún así, es interesante destacar que ya en 1870 el señor Ruscheweyh consta como donante de materiales para el Museo Público $^{12}$. Al mismo tiempo, existen registros que dan cuenta también de que la empresa Ruschaweyh y Cia. estaba vinculada a la importación de diversos materiales para la Universidad de Buenos Aires en 1871 (Ministerio de Gobierno, 1871).

\section{Donación Delfina S. de Viglione (1896)}

Según el mencionado extracto del segundo libro de inventario del MACN, el 6 de noviembre de 1896 se incorpora la donación de la señora Delfina S. de Viglione, viuda de Luis Viglione. La colección de materiales procedentes de Egipto consta de tres números de inventario: "Facsímiles en yeso de varias inscripciones y cuadros bajo relieve egipcios" (lote de cantidad no especificada, No 1.896/3.551), "Varios objetos arqueológicos egipcios" (lote de cantidad no especificada, № 1.896/3.552) y una "Copia en yeso de la cabeza de la reina Ta'schepsut” (No 1.896/3.554). Están incluidos también en la donación "Trozos de moldura estilo corintio". Estos objetos serían parte de la destacada colección adquirida por el arquitecto uruguayo Luis Viglione, durante su viaje por Egipto en 1889 (Santos, 2003).

Actualmente se encuentran asignados al lote 1.896/3.552 un total de nueve objetos (Figura 3). Estas piezas fueron difundidas y valoradas gracias a los trabajos de Rosenvasser y Fuscaldo, en los que se demuestra su relevancia para los estudios egiptológicos. En primer lugar, se encuentran los dos papiros conocidos como "Buenos Aires" y "Khonsu Thot" (Fuscaldo, 1972a; Rosenvasser, 1933, 1972b, 1972c, 1972d). También, dos fardos funerarios de animales momificados, posiblemente de época tardía, uno con forma de gato y otro con forma de halcón (Fuscaldo, 1978a). Luego están incluidos tres ushebty: uno de ellos es de cerámica (Fuscaldo, 1973-1974a, p. 156, lámina IVb); los otros dos, posiblemente de fayenza, son fragmentos que no conservan los segmentos de cabeza y pies (Fuscaldo, 1973-1974a, p. 156, lámina $\mathrm{Va}-\mathrm{Vb}$ ). También está incluida una pequeña estatuilla de cerámica que representa a Bes (Fuscaldo, 1973-1974a, pp. 146-149, lámina IIb). El último de los objetos que hasta el momento pudo asignarse al lote 1.896/3.552 es un fragmento de cartonaje pintado, con inscripciones jeroglíficas, perteneciente a una momia greco-romana. Este fragmento fue asociado erróneamente a la tapa del ataúd masculino (Fuscaldo, 1973-1974b).
11. Esta colección no está incluida en la transcripción que se encuentra en el Museo Etnográfico, realizada por Eric Boman.

12. En 1870, Ruscheweyh dona al Museo Público ejemplares de mariposas (Inventario del Museo Argentino de Ciencias Naturales, 1850-1891, folio 48). 


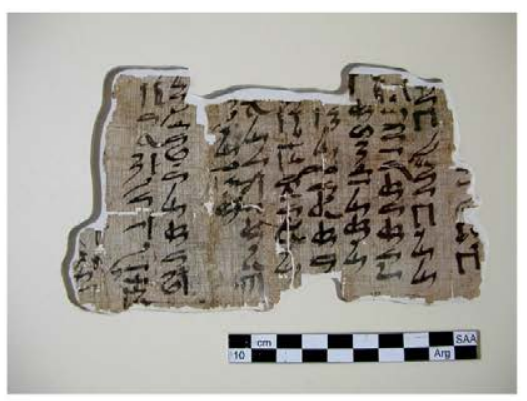

Papiro "Buenos Aires"

Donación Delfina S. de Viglione (1896) № $1896 / 3552$
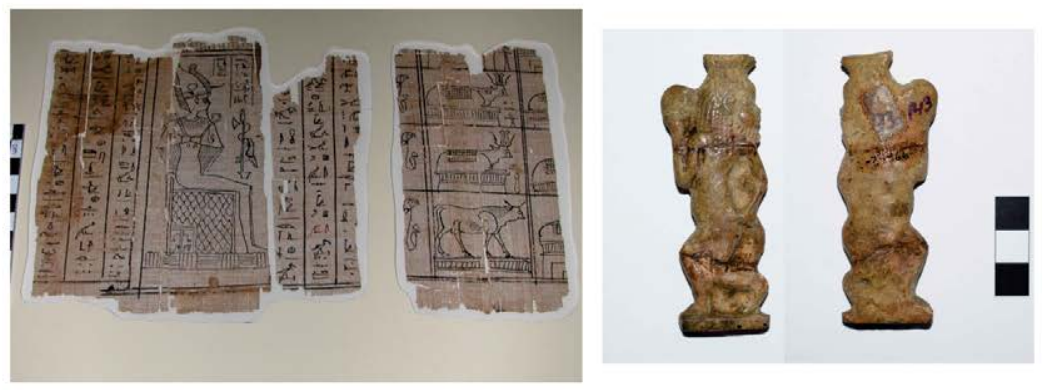

Papiro "Khonsu-Thot"
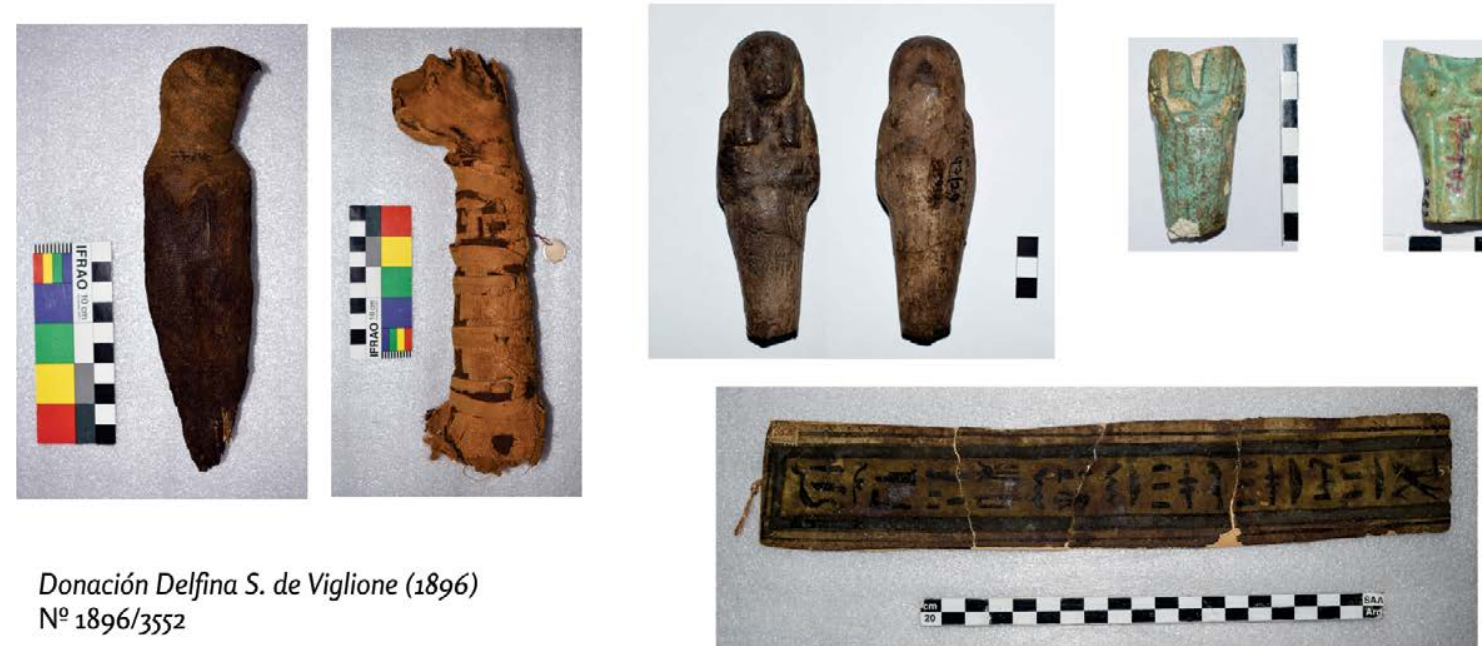

Figura 3. Objetos asignados a la Donación Delfina S. de Viglione (1.896), lote № 1896/3552.

\section{Compra a Gastans Jaliorca (?) (1904)}

En el año 1904 consta el ingreso al antiguo MACN, de un lote de "Dos figuras de tierra cocida, antiguas" procedentes de Egipto (No 1904/4114). Según información del libro original este material fue comprado a Gastans Jaliorca (nombre tentativo dada la dificultad para interpretar la caligrafía original). Estas dos figuras aún no se encuentran identificadas.

\section{Donación Alejandro Marini (o Marissi) (1905)}

En el año 1905 ingresa "Una lámpara griega periodo alejandrino" procedente de Alejandría, Egipto. Esta pieza fue donada por el Sr. Alejandro Marini (o Marissi, caligrafía dudosa). Hasta el momento, esta pieza no ha sido ubicada.

\section{Colecciones Antiguas (1872, ingresada en Catálogo MACN 1935)}

En el catálogo del MACN del año 1935 se consigna la entrada de cuatro objetos. Como información de ingreso se anotó "Colecciones Antiguas" junto con el año 1872. Por lo tanto, se puede considerar que, si bien estos objetos fueron inventariados en 1935, habrían ingresado en realidad al Museo Público en 1872, perdiéndose quizás mayores precisiones contextuales. Según Santos (2003), existe la posibilidad de que estos objetos estén vinculados al escritor Pastor S. Obligado, quien en 1871 visita Egipto como parte de su viaje por Europa y Cercano Oriente. Sin embargo, por el momento no contamos con información concluyente para dar cuenta del origen y forma de ingreso de esta colección. 
Estos objetos, de época tardía, fueron publicados por Fuscaldo (1973-1974a, 1978a) (Figura 4). El conjunto está conformado, según consta en el catálogo, por un "Objeto de cobre, con un gato" ( ${ }^{\circ} 35-499$, procedencia Tebas, Egipto). Esta pieza corresponde al extremo de un objeto indeterminado y representa a la diosa Bastet (Fuscaldo, 1978a, p. 90, lámina IIa). La segunda pieza es un pequeño amuleto colgante de fayenza que representa a Pataikos (Fuscaldo, 1973-1974a, p. 142, lámina I), consignado en catálogo como "Dios Tifón, en piedra" (No 35-500, procedencia Tebas, Egipto). Luego, se encuentra la estatuilla de metal que representa a Osiris momiforme (Fuscaldo, 19731974a, p. 159, lámina VIII) descripta en catálogo como "Dios Osiris, en cobre" (No 35-501, procedencia Egipto). Por último, forma parte de esta colección el ushebty de Padineith, confeccionado en piedra, con superficie esmaltada e inscripciones jeroglíficas (Fuscaldo, 1973-1974a, pp. 153-155, lámina III). En el catálogo se consigna como "Reproducción de un ataúd de momia, en piedra" (№ 35-502, procedencia Egipto).

\section{Colecciones indeterminadas}

Como se muestra en la Tabla 2, se han agrupado un total de 15 objetos dentro del conjunto Colecciones indeterminadas (ver algunos en Figura 5). Se incluyen en este grupo los objetos sin numeración original, aquellos ítems que poseen numeraciones que no remiten a un catálogo conocido y también los ítems cuyo número original fue reasignado en la década de 1970 pero que actualmente son considerados dudosos. Este conjunto está conformado por objetos diversos: cuatro ushebty (Fuscaldo, 19731974a, p. 155-156, lámina IVa, p. 157, lámina VIa, p. 157, lámina VIb), una figura de bronce representando a Thot con cabeza de ibis (Fuscaldo, 1978a, p. 94, lámina Ib), una estatuilla metálica en forma de gato representando a Bastet (Fuscaldo, 1978a, p. 90, lámina Ia), una escultura metálica de Osiris (Fuscaldo, 1973-1974a, p. 159, lámina IX), un colgante con la figura de Sekhmet (Fuscaldo, 1978a, p. 92, lámina IIb), un colgante de Anubis (Fuscaldo, 1978a, p. 93, lámina IIc), un fragmento de colgante de cabeza de Pataikos (Fuscaldo, 1973-1974a, p. 143, lámina IIa), un colgante representando el ojo de Horus, dos sellos escarabeos de piedra, una máscara funeraria de madera y, por último, un calco en yeso de la máscara funeraria del ataúd femenino № -28.105-.

\section{Problemáticas que surgen del relevamiento de las colecciones}

El relevamiento de las colecciones egipcias depositadas en el Área de Arqueología del Museo Etnográfico constituye un proceso continuo de trabajo que genera interrogantes y problemáticas que demandan una profundización de la indagación documental y el desarrollo de nuevos abordajes para la investigación de los objetos. Aquí presentamos tres cuestiones relevantes para el proceso de investigación.

\section{Objetos no ubicados y objetos de Colecciones indeterminadas}

Como se desprende del detalle de las colecciones egipcias, una de las principales cuestiones a resolver es la ubicación/identificación de las distintas piezas consignadas en los catálogos originales. Las colecciones de instituciones históricas como son el MACN y el Museo Etnográfico han sido y son atravesadas por innumerables factores que condicionan su preservación e identidad. Es por esto que el problema de los objetos no ubicados se vincula al de aquellos que no pudieron ser asignados a una colección específica. Esto es así ya que existe la posibilidad de que algunos de estos últimos se correspondan con algunos de los consignados en catálogos, pero que debido a la pérdida de su información asociada (inscripciones, rótulos, etiquetas, entre otros) no pudieron ser identificados. Por ejemplo, varios posibles ushebty no ubicados (Donación Gregoria Ezcurra de Cálvari 1880, Compra a Gastans Jaliorca 1904, Donación Héctor Ambrosetti 1914) podrían vincularse a algunos de los ítems sin número original. También sería el caso del "Ídolo 


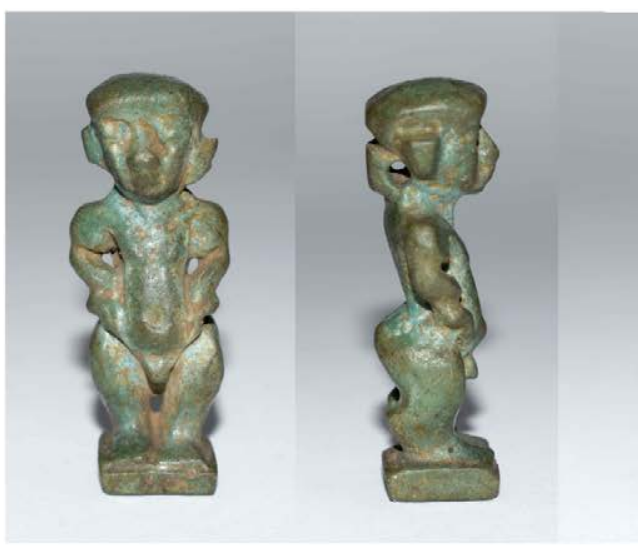

№ $35-500$

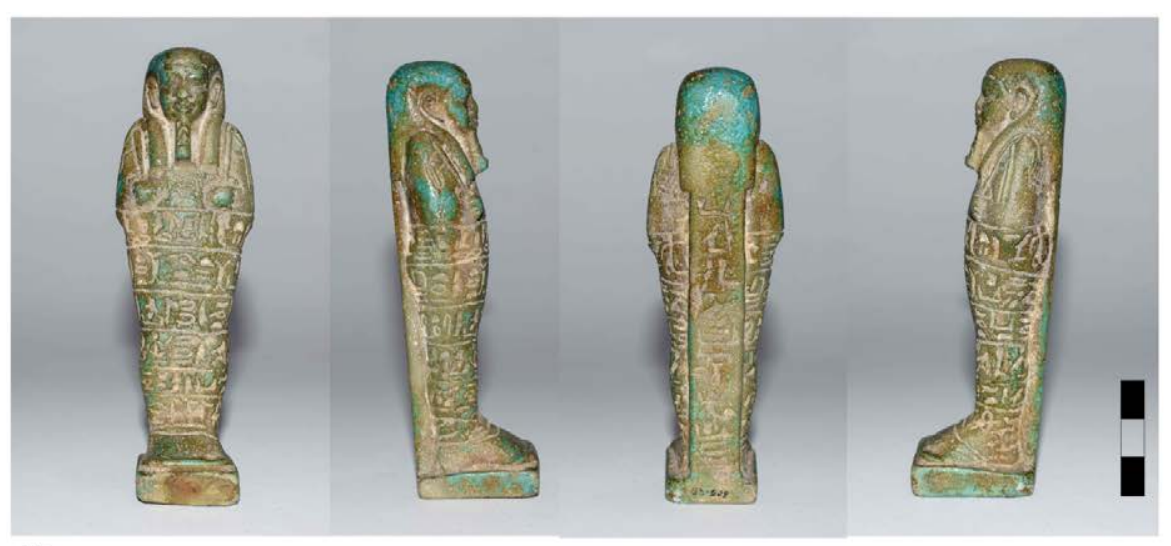

№ $35-502$

Colecciones Antiguas (1872, ingresada en Catálogo MACN 1935)

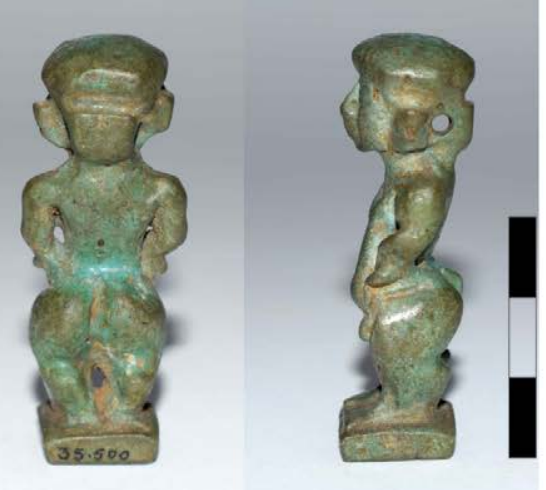

№ $35-499$

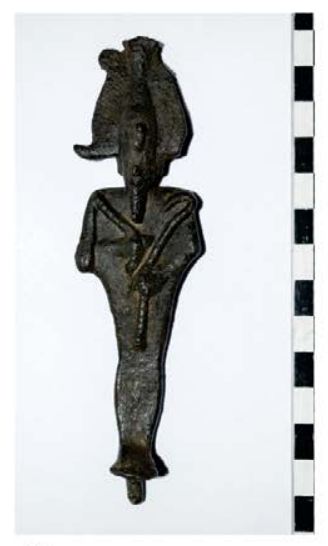

№ $35-501$

Figura 4. Objetos pertenecientes a Colecciones Antiguas (1872, ingresada en Catálogo MACN 1935).

de bronce" no ubicado (Compra 1914) que podría corresponderse con algunos de los objetos metálicos sin numeración original. Por su parte, la máscara funeraria de colección indeterminada podría ser parte del cuarto ataúd no conservado (Santos, 2007). A su vez, cabe la posibilidad de que los objetos sin numeración original formaran parte del lote "Varios objetos arqueológicos egipcios" de la Donación Delfina S. de Viglione.

$\mathrm{Al}$ mismo tiempo, se debe considerar que algunas de las piezas que no pudieron vincularse a una colección específica puedan pertenecer a otras colecciones que no fueron consignadas en los catálogos (al menos conocidos). En este sentido es interesante mencionar el siguiente ejemplo.

Según documentos relevados, la Universidad de Buenos Aires recibe en 1873, de parte de P. Dupuis, la donación de una colección de antigüedades egipcias y monedas antiguas. La misma fue aceptada y agradecida por el Rector, Juan María Gutiérrez y el Ministro de Gobierno, Amancio Alcorta (Alcorta, 1873; Dupuis, 1873; Gutiérrez, 1873). El Rector, en el borrador de una nota a Dupuis, afirma: "He acusado recibo de su nota, dándole las gracias y he colocado los objetos de su donación en el lugar que he creido mas aproposito en este establecimiento" (Gutiérrez, 1873, ortografía original). Sin embargo, no encontramos datos específicos vinculados con el destino de esta colección. No obstante y a pesar de que esta donación no está consignada en los libros de inventario del Museo Público, es muy probable que la misma se remitiera a éste, ya que compartía su emplazamiento con la Universidad en el edificio de la Manzana de las Luces y, además, había dependido de esta casa de estudios durante tres décadas. 


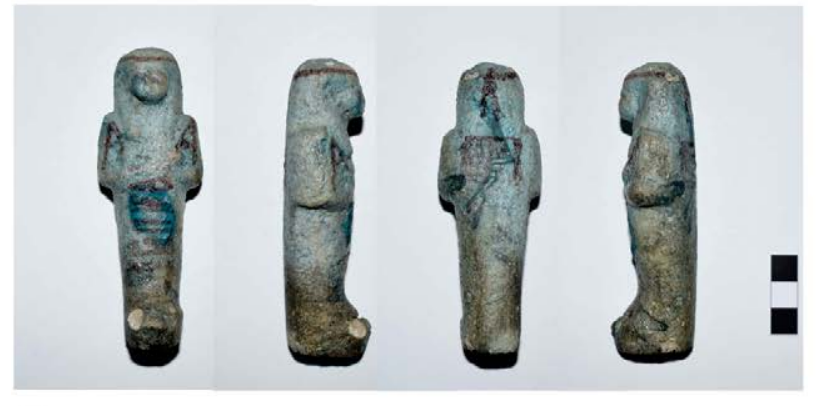

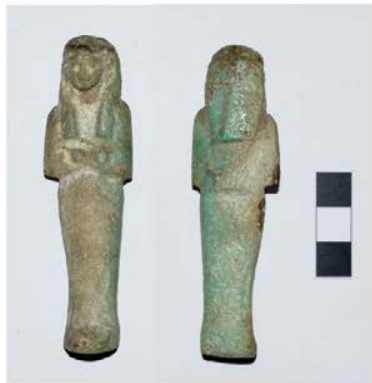

№-40482-

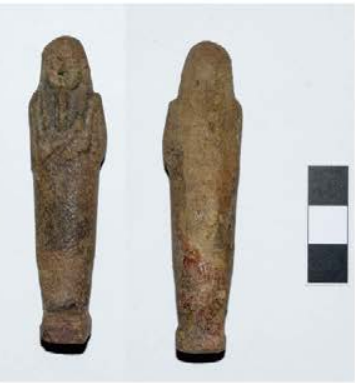

№-40483-

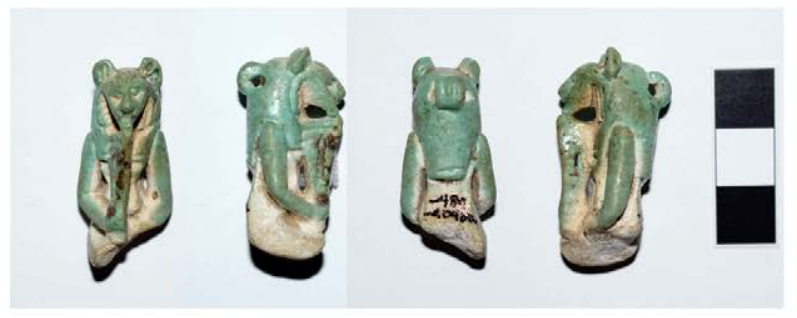

№ $-40480-$
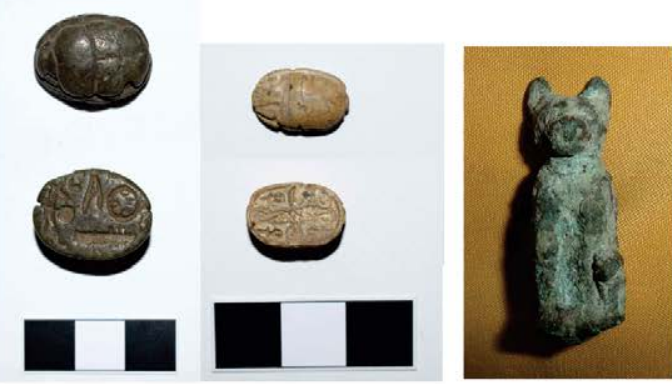

№-40487-

№-29964-

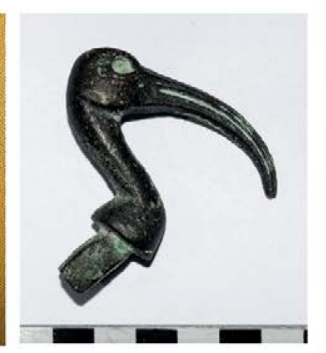

№ -29965 -
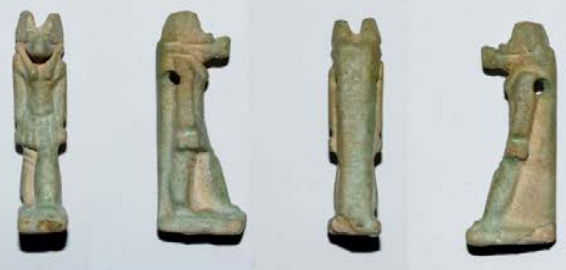

№-40481-

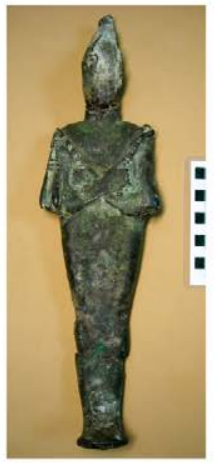

S/No

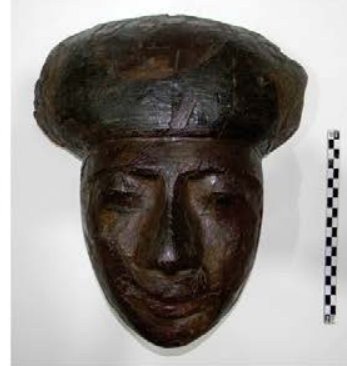

№ X-66-2

Colecciones indeterminadas

Figura 5. Algunos objetos del conjunto Colecciones indeterminadas.

Según se puede extraer de la nota del 23 de junio de 1873 que Dupuis escribe al Rector de la Universidad, la colección donada estaba conformada por los siguientes objetos:

"Un broncecito representando a la diosa "Bast" con cabeza de gata

"Un amuleto del dios "Thot" con cabeza de Ibis

"Un amuleto de la diosa "Sekhet" con cabeza de leona

»Un amuleto de "Osiris"

"El "Mat"

»Dos pequeñas estatuas funerarias

"Un escarabajo funerario

"Un aderezo

»Una colección de ocho piezas antiguas y modernas de moneda

»Tres amonitas fósiles de Europa (Dupuis, 1873, ortografía y subrayados originales)

Según esta descripción, es factible que algunos de los 15 objetos sin numeración original (o con asignaciones dudosas) que se han ubicado en el Área de Arqueología puedan pertenecer a esta colección. Para algunos de los ítems enumerados, Dupuis ofrece información vinculada con su procedencia, la cual deberá considerarse en el análisis 
13. Si bien no se aclara el sustento de esta mención, resulta interesante para explorar. ¿Esto podría implicar entonces que, al igual que los ataúdes ingresados en 1848 , también el de 1842 vinculado a Rosas haya sido colectado por Thondicke? Aunque sin utilizar esta fuente, también Santos (2003, p. 61 , Nota 7) realiza un planteo vinculado a esta idea. de este documento y su posible vinculación con algunos de los objetos actualmente depositados en el Museo Etnográfico.

\section{El problema de la identificación de los ataúdes}

Según lo desarrollado previamente, aún esperando mayor sustento documental, se puede sostener que en 1842 habría ingresado al antiguo MACN, por orden de Juan Manuel de Rosas, un ataúd egipcio (y momia) perteneciente a una mujer. Asimismo, en 1848 habrían ingresado por donación del comerciante norteamericano Thomas Thondicke, tres ataúdes (y momias), uno femenino y dos masculinos. Teniendo en cuenta que en el Museo Etnográfico se conservan los restos de sólo tres sarcófagos de madera, surge como problemática relevante la posibilidad de identificar cuál sería la pieza ingresada en 1842 (vinculada a Rosas) y cuáles serían las correspondientes a la donación realizada por Thondicke en 1848 (que, según las fuentes, provendrían de Saqqarah).

La tradición oral transmitida dentro del Museo Etnográfico sostenía que el ataúd de Amenirdis era el vinculado con la figura de Juan Manuel de Rosas, quien lo habría recibido como obsequio del gobierno francés. Existe otra fuente que menciona que esta pieza "fue obsequiada a don Juan Manuel de Rosas por un súbdito inglés"13 (Municipalidad de la Ciudad de Buenos Aires, 1954, p. 22). Aunque se observan diferencias en cuanto a quién realiza el presente, ambas versiones coinciden en que este ataúd fue entregado a Juan Manuel de Rosas. Sin embargo, hasta el momento no se conocen otros documentos que permitan corroborar esta posibilidad.

De las fuentes que hacen referencia al ataúd que ingresa en 1842 (Inventario 1842-1849 "Registro de los efectos que han sido donados al Museo de Historia Natural de Buenos Aires..." en Castello, 2014; Inventario del Museo Argentino de Ciencias Naturales, 18501891; Trelles, 1854) sólo Trelles describe alguna de sus características, al plantear que la caja que contiene a la momia está "cubierta de inscripciones y jeroglíficos egipcios" (Trelles, 1854, p. 9). No obstante, esta referencia resulta muy difícil de asociar a alguno de los ataúdes en particular.

Por su parte, las fuentes que mencionan los sarcófagos donados por Thondicke en 1848, principalmente Carranza (1865) y Fontana (1870), ofrecen otros elementos interesantes (asumiendo que efectivamente estos autores hacen referencia exclusivamente a los ataúdes de 1848). En primer lugar, Carranza (1865, p. 239) afirma que los sarcófagos de las tres momias egipcias estaban "cuajados de jeroglíficos coptos". Teniendo en cuenta también aquella tradición oral que vinculaba el ataúd de Amenirdis con Juan Manuel de Rosas (cuya entrada sería en 1842), Santos (2007, p. 52) intenta sostener esta posibilidad diciendo que Trelles (1856) destacaba que el único ataúd existente en el museo estaba "cuajado de jeroglíficos coptos". Dado que, según Santos (2007, p. 52), el de Amenirdis es el que posee más texto jeroglífico, se plantea que éste puede corresponder entonces al que ingresa en 1842. Sin embargo, como vimos, es Carranza (y no Trelles) el que afirma esta característica, pero para los tres sarcófagos de 1848 (y no para el de 1842). Siguiendo la argumentación de Santos, ¿podría pensarse entonces que dentro del conjunto donado por Thondicke se encontraba el de Amenirdis?

Por otro lado, también Fontana describe, en este caso más detalladamente, los tres ataúdes introducidos por Thondicke en 1848, afirmando que se trata de dos masculinos y uno femenino. Al referirse a la tapa externa del ataúd femenino, menciona que se puede observar "una joven con alas estendidas (sic) y sustentando el mundo en la cabeza" (Fontana, 1870, p. 513). El aporte de este detalle es sumamente interesante, ya que podría tratarse de la diosa Nut que despliega sus alas bajo el rostro en la tapa externa del sarcófago de Amenirdis. El otro ataúd femenino que se conserva en el Museo Etnográfico ( $\left.\mathrm{N}^{\circ}-28.105-\right)$ no conserva decoración en la tapa externa y tampoco presenta la imagen mencionada en su cara interna. 
En definitiva, estos puntos planteados aquí brevemente, introducen nuevas dudas con relación a las trayectorias históricas de estas colecciones, las cuales involucran la procedencia como dato fundamental para las investigaciones en torno a estas piezas centrales de la egiptología argentina.

\section{El problema de la autenticidad}

Otra problemática que surge del relevamiento de las colecciones está vinculada con la autenticidad de algunos objetos. Esta es una temática compleja teniendo en cuenta tanto la existencia de falsificaciones de época para algunos tipos de objetos egipcios como la circulación y mercantilización de antigüedades egipcias durante el siglo XIX y principios del XX. Como se verá en la siguiente sección, para el abordaje de esta problemática es fundamental el desarrollo de nuevas vías de aproximación a los objetos.

\section{Investigación en conservación}

La investigación de colecciones involucra la preservación de las mismas. Es así que los trabajos de conservación en sus distintas acepciones (conservación preventiva, conservación remedial) se presentan como necesarios e indispensables para prevenir el deterioro y salvaguardar el valor tangible e intangible del patrimonial cultural.

Si bien los trabajos de conservación que se practican sobre objetos y/o colecciones, pueden darse sobre el medioambiente de depositación o guarda de los bienes, lo que supone la utilización de materiales de embalaje y soportes propicios y la aplicación de distintos tipos de tratamientos y gradientes de intervención, ninguna práctica específica puede realizarse sin una investigación de conservación previa y concreta según los objetivos del proyecto que se lleva adelante.

En el caso de las colecciones egipcias del Museo Etnográfico, los trabajos de investigación incluyen también la conservación de este patrimonio. Es por eso que con el propósito de determinar cuáles son las necesidades para la adecuada preservación del mismo, se investiga sobre el diagnóstico y tratamiento de los objetos. A tal fin, para llevar adelante el trabajo con las colecciones egipcias se realizó un relevamiento documental mediante fichas y fotografías del estado de conservación, registrando, entre otros aspectos, los distintos deterioros, los materiales constitutivos y técnicas de manufactura observables.

Un aspecto importante de la investigación en conservación gira en torno a las problemáticas que se vinculan a la pérdida de información asociada físicamente a los objetos, a la presencia de réplicas y falsificaciones en las colecciones y a la existencia de piezas que presentan agregados o reconstrucciones parciales difíciles de diferenciar de sus partes originales.

\section{Antecedentes en trabajos de conservación}

La mayor parte de los objetos egipcios del museo procede de colecciones particulares formadas en el siglo XIX que ingresaron al Museo Etnográfico y al MACN en distintos años, careciendo de documentación que diera cuenta del estado de conservación de los mismos. Aunque como ya se mencionó, hay algunas publicaciones que analizan objetos de las colecciones, hasta el momento no hay antecedentes de trabajos que traten específicamente la cuestión de la preservación. Sin embargo, existen dos informes que describen parámetros relacionados al estado de conservación del ataúd de madera con decoración policroma e inscripciones jeroglíficas que perteneció a una mujer llamada Amenirdis, de época Tardía (Bonanno, 2019; Fuscaldo, 1972a; Santos, 2003, 2004) (No -28.104-). Estos son el Informe interno del museo presentado por la conservadora Norma 
Pérez en el año 1996 — producto de los trabajos que realizó en el objeto años anteriores-, y el informe de conservación realizado por D. González Pondal y G. Ammirati del año 1998 llevado a cabo en el marco de un curso de conservación efectuado por la Fundación Antorchas. Además, para este objeto, se cuenta con algunas fotografías antiguas en soporte vidrio (AMEJBA) donde se puede apreciar el estado estructural del ataúd. También, encontramos el artículo de Bonanno (2019) que, aunque no se adentra en temas específicos de conservación, describe cuestiones relacionadas, como por ejemplo el estado estructural general de la pieza, medidas, faltantes, pigmentos. Por otra parte, Santos (2007) nombra un documento de noviembre de 1842, donde se mencionan los gastos económicos que demandaron los arreglos del cajón de una momia. Aunque no se precisa cuáles fueron los trabajos específicos que se llevaron a cabo, nos da un indicio del período temporal en donde ya se habrían practicado actividades de restauración sobre uno de los ataúdes. También, como se mencionó anteriormente, hay fotografías en soporte vidrio que muestran el estado integral general de otro ataúd ( $\mathrm{N}^{\circ}$-28.105-).

No obstante, la información de conservación de los distintos objetos egipcios del Museo es muy escasa. Ante esto, consideramos importante realizar un pormenorizado trabajo de documentación que diera cuenta del estado actual de estas colecciones y de los deterioros que presentan. Se buscó también implementar estudios analíticos que permitieran abordar problemas vinculados con la caracterización y conservación de estos objetos.

\section{Documentación y aplicación de técnicas analíticas}

Para ahondar en las cuestiones de conservación del patrimonio arqueológico egipcio y en función del trabajo de documentación que se lleva a cabo, en una primera etapa se seleccionó un conjunto de objetos que se ajustaban para el desarrollo y contrastación de las problemáticas planteadas. Se practicaron sobre estos objetos distintas técnicas de análisis dando prioridad a aquellas de carácter no destructivo o que requirieran la toma de mínimas muestras.

Las técnicas analíticas realizadas comprendieron tomas fotográficas con luz rasante, luz UV e infrarroja; radiografía digital directa (realizadas por el médico veterinario Martín Gaggiotti, de la Universidad Nacional de La Plata), fluorescencia de rayos X con equipo portátil (efectuada por la Dra. María Teresa Plaza de la University College London) y microscopía óptica (realizada por Martínez y Gelabert de INTI Textiles).

Los objetos a los que se les practicaron distintos tipos de análisis fueron los dos fardos funerarios de animales, uno en forma de gato y el otro en forma de ave (Donación Delfina S. de Viglione, Figura 3), dos estatuillas metálicas de Osiris (una perteneciente a Colecciones Antiguas 1872, Figura 4, № 35-501 y otra a Colecciones indeterminadas, Figura 5, S/No), una cabeza en metal de ibis representación del dios Thot (Colecciones indeterminadas, Figura 5, No -29.965-) y dos pequeñas esculturas metálicas de gato que representan a la diosa Bastet (una perteneciente a Colecciones Antiguas 1872, Figura 4, No 35-499 y otra a Colecciones indeterminadas, Figura 5, No -29.964-). También se realizaron distintos estudios a la tapa del ataúd de Amenirdis (Figura 2A).

En el caso de las momias de animales, teniendo en cuenta la existencia de falsificaciones actuales y de época (Ikram, 2012), consideramos relevante conocer el contenido de los fardos. Para ello se aplicó la técnica de radiografía digital directa, la cual mostró que el interior del fardo en forma de halcón contiene restos esqueletales de un ave, mientras que la momia de gato presenta restos mineralizados sin poder determinarse aún con exactitud su naturaleza (Figura 6) (Ammirati et al., 2018; Marchegiani et al., 2018).

Otra técnica practicada en ambos fardos fue el análisis microscópico de las fibras del envoltorio, para lo cual se tomaron en cada objeto dos muestras correspondientes a 


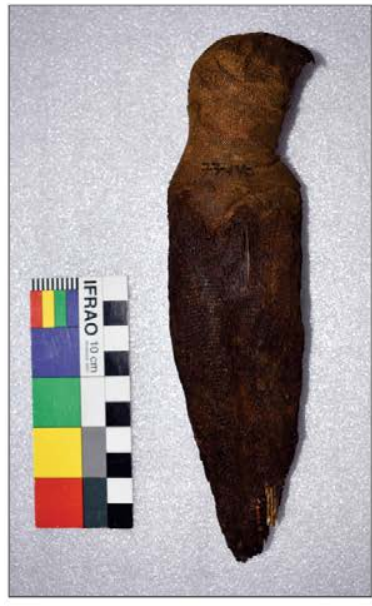

Momias de animales

№ 1896/3552, Donación Delfina S. de Viglione (1896)
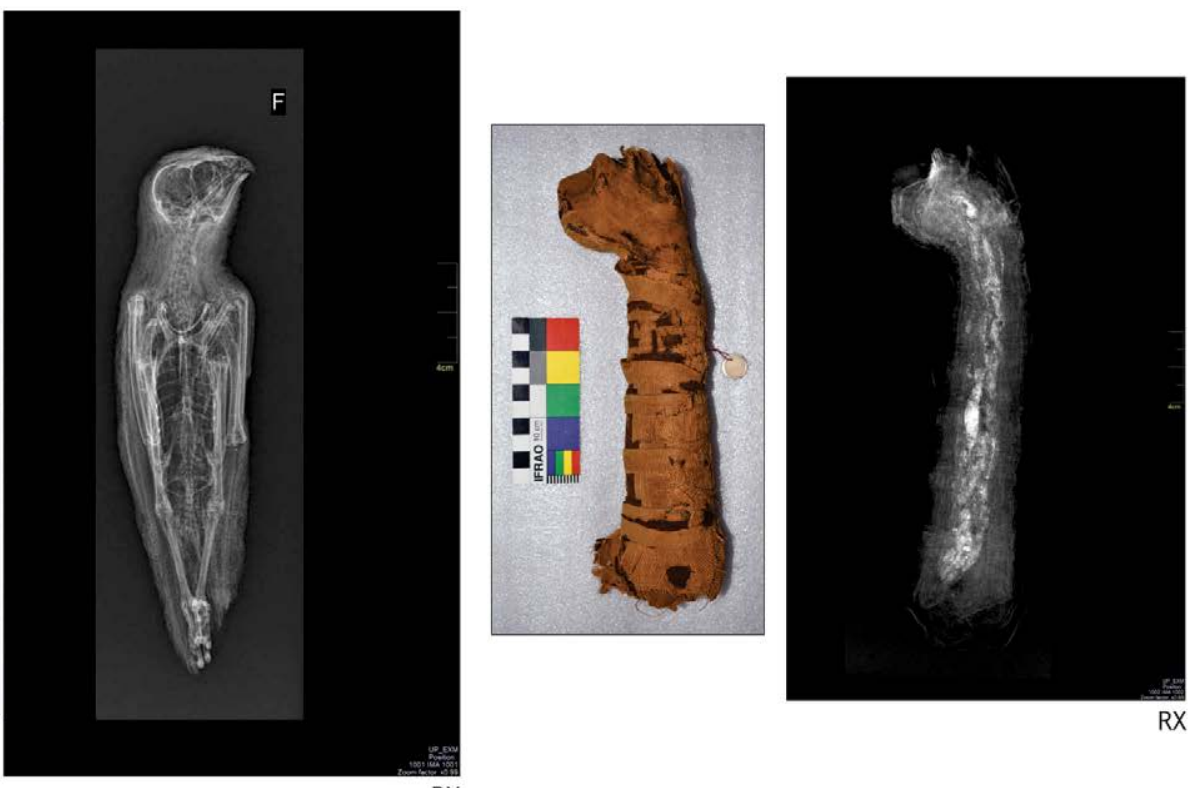

$\mathrm{RX}$

Figura 6. Momias de animales en forma de halcón y gato, correspondientes al lote № 1896/3552, Donación Delfina S. de Viglione (1896). Examinación a través de radiografías digitales de imagen directa $(R X)$.

textiles diferentes. En la momia de ave se reconoció por un lado una estructura de "ligamento tafetán" y por otro, una estructura de "ligamento no identificado". En la momia de gato se identificaron dos tipos de estructuras: una es "ligamento tafetán" y la otra "ligamento panamá". El análisis microscópico indicó que todas las muestras analizadas corresponden a lino y que se encuentran muy dañadas en su estructura (Martínez y Gelabert, 2018).

Las cinco estatuillas metálicas mencionadas fueron examinadas mediante radiografías digitales de imagen directa que permitieron identificar detalles del proceso de manufactura. Se reconocieron así dos piezas macizas (Figura 4, № 35-499 y Figura 5, No -29.965-), una hueca con estructura de sostén interna (Figura $5, \mathrm{~S} / \mathrm{N}^{\circ}$ ) y otra que presenta una zona maciza combinada con un segmento hueco (Figura 5, No -29.964-). Una estatuilla se encuentra aún en proceso de interpretación (Figura 4, № 35-501).

A cuatro de estos cinco objetos metálicos se les realizó además estudios de Fluorescencia de rayos $\mathrm{X}$ con equipo portátil (FRXp), técnica no destructiva que permitió obtener una primera aproximación a la composición química elemental. Teniendo en cuenta que las superficies de los objetos no fueron preparadas retirándoles pátinas o productos de corrosión, los datos obtenidos son de carácter cualitativo, marcando presencia/ausencia de elementos. Así, los estudios indicaron la presencia de cobre, estaño y plomo en la superficie de la figura de Ibis (Figura 5, № -29.965-). En la estatuilla de Osiris analizada (Figura 4, No 35-501) y en una de las figuras de gato (Figura 4, № 35-499) se registró cobre y plomo, mientras que el estaño se observó en una sola de las tres lecturas realizadas sobre cada pieza. En la otra figura de gato (Figura 5, № -29.964-) se identificaron cobre y plomo, pero no estaño (Plaza, 2017). Si bien los resultados obtenidos dieron cuenta de elementos compatibles con la producción metalúrgica del antiguo Egipto (Schorsch, 2007), serán necesarios otros estudios (posiblemente con toma de muestras) para lograr mayor precisión en la identificación y cuantificación composicional.

Por último, la tapa del ataúd de madera de Amenirdis fue examinada a través de fotografías con luz rasante, con luz UV y con infrarrojos (IR) (Figura 7), que aportaron 
Ataúd de Amenirdis (№ -28104-)

Tapa externa
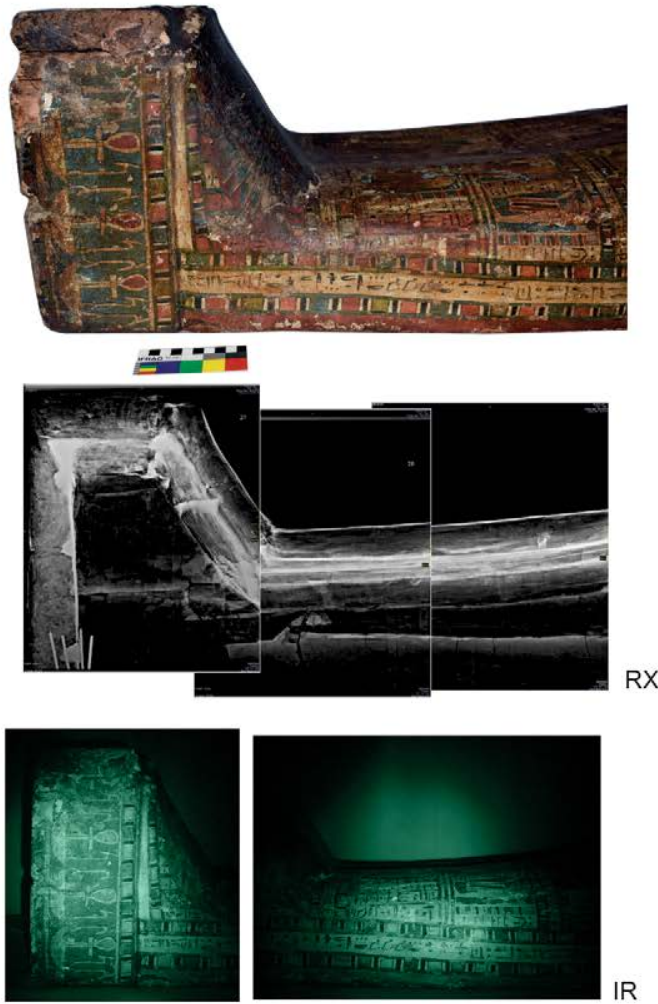

IR
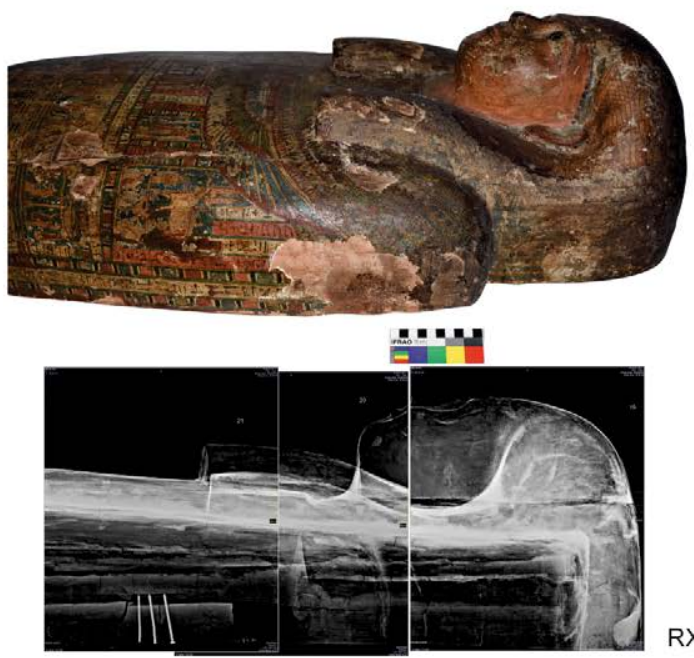

$\mathrm{RX}$
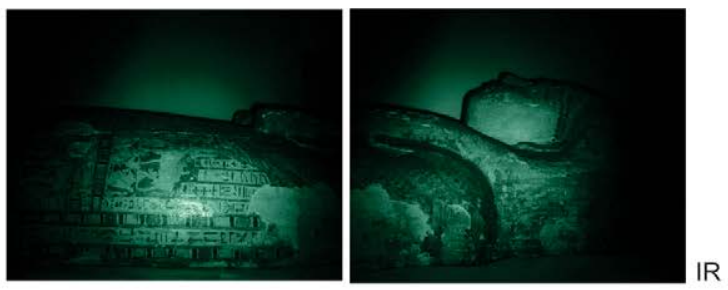

IR

Vista lateral

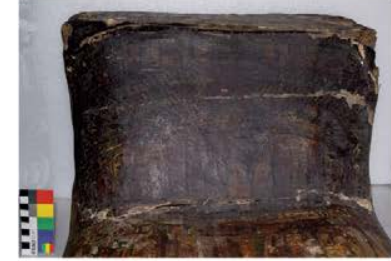

Detalles
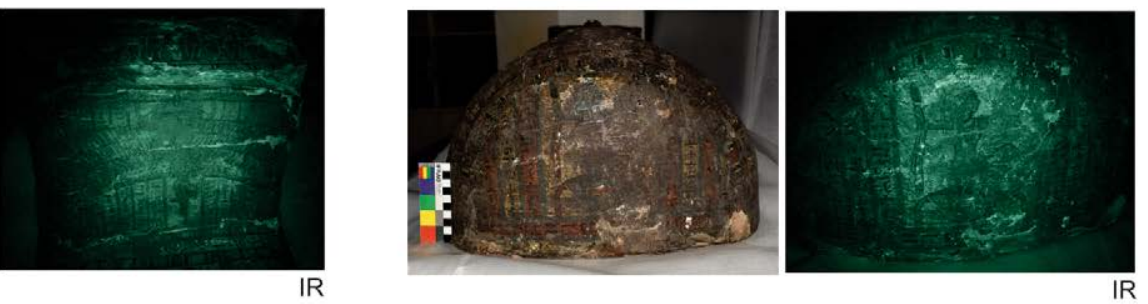

Figura 7. Vista lateral y detalles de la tapa externa del ataúd de Amenirdis (№ -28.104-). Examinación a través de fotografía infraroja (IR) y radiografías digitales de imagen directa $(R X)$.

información diversa y complementaria sobre el estado de conservación y los deterioros presentes en su capa de imprimación y pictórica. Por ejemplo, a partir de fotografías IR se pudieron observar en el empeine y en la parte superior de la cabeza motivos iconográficos que actualmente no son visibles a ojo desnudo debido al oscurecimiento de la capa de barniz que recubre al objeto (Figura 7). También se realizaron radiografías digitales de imagen directa que brindaron información sobre su estructura interna y materiales constitutivos. Se identificaron listones y segmentos de madera modeladas que se encastran entre sí, observándose que algunos presentan grietas y roturas. Además, se registró la presencia de clavos metálicos de características modernas, probablemente de restauraciones realizadas en la primera mitad del siglo XX.

Los trabajos de documentación del estado de conservación de los distintos objetos egipcios están en pleno proceso. Las distintas técnicas analíticas empleadas y por emplear aún, aportarán datos más precisos sobre la caracterización de los objetos y 
para la toma de decisiones en cuanto a los tratamientos de conservación a realizar. Pensamos desarrollar líneas de investigación que involucren otros estudios, como dataciones, tomografía computada, identificación taxonómica de restos botánicos y animales, análisis químicos de pigmentos, identificación de residuos orgánicos y otros materiales.

Los resultados obtenidos de la aplicación de distintas técnicas y análisis requieren ser trabajados conjuntamente y valorarse de manera integral junto con los datos alcanzados mediante los estudios estilísticos de los objetos y la indagación de las distintas fuentes de documentación disponibles.

Por el momento, aunque preliminares, las investigaciones que se están desarrollando sobre el estado de la materialidad de los objetos arqueológicos del Museo contribuirán a la puesta en valor de las colecciones y su preservación.

\section{Consideraciones finales}

El proyecto de investigación de las colecciones egipcias del Museo Etnográfico "Juan B. Ambrosetti", se enmarca dentro de los objetivos de trabajo del Área de Arqueología. Si bien hemos avanzado en la búsqueda documental que nos permite indagar sobre los derroteros históricos de estas colecciones, como también en parámetros de la conservación de los objetos egipcios aplicando, entre otras cosas, distintas técnicas analíticas, los resultados aquí presentados son de carácter preliminar y se desarrollan dentro de un proyecto amplio y de largo plazo.

Consideramos que los trabajos que desarrollamos constituyen un aporte para la preservación de las colecciones y para los especialistas en el estudio de estos materiales.

\section{Agradecimientos}

A Diego Santos. A Violeta Pereira. A Marisa Scarafoni del Archivo Fotográfico y Documental del Museo Etnográfico "Juan B. Ambrosetti" (Facultad de Filosofía y Letras, Universidad de Buenos Aires). A Lucía Wisnieski del Archivo Histórico de la Universidad de Buenos Aires "Presbítero Antonio Sáenz". A Ignacio Legari del Archivo Histórico del Museo Argentino de Ciencias Naturales "Bernardino Rivadavia". A Raúl Robles del Archivo General de la Facultad de Filosofía y Letras (Universidad de Buenos Aires). A la Dra. María Teresa Plaza de la University College London. Al Médico Veterinario Martín Gaggiotti de la Universidad Nacional de La Plata. A Laura Martínez y Laura Gelabert de INTI Textiles. Al personal de las Áreas de Etnografía y Conservación y Museografía del Museo Etnográfico. A los evaluadores anónimos, cuyos comentarios nos permitieron mejorar el manuscrito. Este trabajo se realizó en el marco del proyecto ANPCyT PICT 2015-1394, dirigido por la Dra. Mónica Berón. 


\section{Q Referencias citadas}

"Alcorta, A. (1873, Julio 7). Carta del Ministro de Gobierno. Fondo Rectorado (48-0219). Archivo Histórico de la Universidad de Buenos Aires "Presbítero Antonio Sáenz", Ciudad de Buenos Aires.

" Ammirati, G., Coll Moritan, V. y Manuale, S. (2008). Puesta en valor de las colecciones arqueológicas del Museo Etnográfico “J. B. Ambrosetti”. Trabajo presentado en Actas de las l’a Jornadas de Educación e Investigación en los Museos [CD ROM]. Santa Fe, Argentina.

"Ammirati, G., Coll Moritan, V., Reynoso, A. y Manuale, S. (2010). Colección de “La Pampa Grande" (Salta). Primera expedición del Museo Etnográfico (Facultad de Filosofía y Letras, UBA). Trabajo presentado en Actas Primer Congreso Nacional de Museos Universitarios, [CD ROM]. La Plata. Argentina.

"Ammirati, G., Estevez, J. M., Marchegiani, M. y Reynoso A. (2018). Utilización de técnicas analíticas para el estudio de objetos arqueológicos del Museo Etnográfico "Juan B. Ambrosetti”. En VI Encuentro Internacional de Conservación y Restauración. https:// docs.wixstatic.com/ugd/331d48_baza7b9f331c4472887c9d93289fe48o.pdf (Acceso: 15 de marzo, 2019)

" Asúa, M. de (2012). Dos siglos y un museo. En P. Penchaszadeh (Ed.), El Museo Argentino de Ciencias Naturales. 200 años (pp. 13-70). Buenos Aires: Museo Argentino de Ciencias Naturales.

» Bonanno, M (2019). El sarcófago de Amenirdis (Inv. -28104-). Apuntes en relación a su programa iconográfico y textual. Sitio de procedencia, datación y depositación. Arqueología, 25(1), 187-201.

»Burmeister, G. (1864). Sumario sobre la fundación y los progresos del Museo público de Buenos Aires. Anales del Museo Público de Buenos Aires, 1, 1-11.

"Carranza, A. J. (1865). Anales del Museo Público de Buenos Aires. La Revista de Buenos Aires, VII, 235-243.

" Castello, H. P. (2014). La Historia del Museo Público de Buenos Aires (1812-1884). Cuadernos "Manzana de Las Luces. Crónicas de su historia", 11, 6-20.

"Dupuis, P. (1873, Junio 23). Carta del 23 de Junio de 1873. Fondo Rectorado (48-01-50). Archivo Histórico de la Universidad de Buenos Aires "Presbítero Antonio Sáenz", Ciudad de Buenos Aires.

"Fontana, L. J. (1870). El Arte de Embalsamar y las momias egipcias y peruanas del Museo Público de Buenos Aires. La Revista de Buenos Aires, XXIII, 506-520.

» Fuscaldo, P. (1972a). El papiro funerario de Khonsu Thot (Frag. 1). Revista del Instituto de Historia Antigua Oriental, 1, 57-64.

» Fuscaldo, P. (1972b). El ataúd de Amenardis. Revista del Instituto de Historia Antigua Oriental, 1, 65-98.

» Fuscaldo, P. (1973-1974a). Las estatuillas. Revista del Instituto de Historia Antigua Oriental, 2, 138-158.

" Fuscaldo, P. (1973-1974b). Restos de un ataúd. Revista del Instituto de Historia Antigua Oriental, 2, 159-166.

" Fuscaldo, P. (1978a). Estatuillas y animales momificados. Revista del Instituto de Historia Antigua Oriental, 4, 87-95. 
»Fuscaldo, P. (1978b). La tabla funeraria del ataúd de Amenardis. Revista del Instituto de Historia Antigua Oriental, 4, 96-98.

» González Pondal, D. y Ammirati, G. (1998). Informe de conservación realizado en el marco del Curso de Conservación Preventiva de la Fundación Antorchas. Manuscrito inédito.

» Gutiérrez, J. M. (1873, Junio 28). Carta del Rector de la Universidad de Buenos Aires. Fondo Rectorado (48-02-09). Archivo Histórico de la Universidad de Buenos Aires "Presbítero Antonio Sáenz", Ciudad de Buenos Aires.

»Ikram, S. (2012). Creatures of the gods: animal mummies from ancient Egypt. Anthronotes, 33(1), 1-5.

» Inventario del Museo Argentino de Ciencias Naturales (1850-1891). Archivo Histórico del Museo Argentino de Ciencias Naturales “Bernardino Rivadavia”, Ciudad de Buenos Aires.

» Legajo 18o MCN (n.d.). Archivo Fotográfico y Documental del Museo Etnográfico “Juan B. Ambrosetti”, Facultad de Filosofía y Letras, Universidad de Buenos Aires, Ciudad de Buenos Aires.

» Libro Copiador del Museo Argentino de Ciencias Naturales (1925-1928). Archivo Fotográfico y Documental del Museo Etnográfico “Juan B. Ambrosetti”, Facultad de Filosofía y Letras, Universidad de Buenos Aires, Ciudad de Buenos Aires.

» Marchegiani, M., Reynoso, A., Ammirati, G. y Estevez, J. M. (2018). La aplicación de técnicas analíticas para el estudio y conservación de las colecciones egipcias del Museo Etnográfico “J. B. Ambrosetti”. En J. Sellés Martínez (Ed.), 1ํㅡ Reunión Internacional Intersecciones Ciencia, Arte y Patrimonio (pp. 63-66). Buenos Aires: Instituto de Micología y Botánica Ediciones.

» Martínez, L. y Gelabert, L. (2018). Informe técnico sobre muestras textiles del Museo Etnográfico “Juan B. Ambrosetti”, FFyL, UBA. INTI Textiles. Informe al Museo Etnográfico. Manuscrito inédito.

» Ministerio de Gobierno (1871, Diciembre 27). Carta del 27 de Diciembre de 1871. Fondo Rectorado (42-02-39). Archivo Histórico de la Universidad de Buenos Aires "Presbítero Antonio Sáenz", Ciudad de Buenos Aires.

» Moret, A. (1925, 27 de septiembre). Ataúdes Egipcios del Museo de Historia Natural de Buenos Aires, por Alexandre Moret, Profesor de Egiptología del Colegio de Francia, La Nación, pp 5.

» Municipalidad de la Ciudad de Buenos Aires (1954). Exposición Universal de la Máscara. Buenos Aires: Departamento de Publicaciones y Ediciones de la Dirección de Bibliotecas Públicas Municipales.

» Outes, F. (1934, Noviembre 26). Carta del Director de Museo Etnográfico. Sección Museo Antropológico y Etnográfico (Institutos) [Caja 77, B-5-13 (40)]. Archivo General de la Facultad de Filosofía y Letras, Universidad de Buenos Aires, Ciudad de Buenos Aires.

»Outes, F. (1935, Enero 10). Carta del Director de Museo Etnográfico. Sección Museo Antropológico y Etnográfico (Institutos) [Caja 77, B-5-13 (41)]. Archivo General de la Facultad de Filosofía y Letras, Universidad de Buenos Aires, Ciudad de Buenos Aires.

»Perazzi, P. (2008). Derroteros de una institución científica fundacional: el Museo Público de Buenos Aires, 1812-1911. Runa, 29, 187-206.

» Pérez, N. (1996). Informe interno del Área de Conservación del Museo Etnográfico. Manuscrito inédito. 
»Pistacchi, M. A. (2012). El Orientalismo en Argentina. La Creación de la Identidad y sus Instituciones. Berlín: Editorial Académica Española.

"Plaza, M. T. (2017). Análisis de fluorescencia de rayos $\mathrm{X}$ exploratorio en piezas metálicas almacenadas en el Museo Etnográfico "Juan B. Ambrosetti”, FFyL, UBA. Informe al Museo Etnográfico. Manuscrito inédito.

»Podgorny, I. (2009). El sendero del tiempo y de las causas accidentales. Los espacios de la prehistoria en la Argentina, 1850-1910. Rosario: Prohistoria Ediciones.

» Podgorny, I. y Lopes, M. M. (2008). El desierto en una vitrina. Museos e historia natural en la Argentina, 1810-189o. México: Editorial LIMUSA.

》Reynoso, A. y Ammirati, G. (2013). Los discos de bronce con numeración grabada del Museo Etnográfico "Juan B. Ambrosetti" (FFyL, UBA). Trabajo presentado en el XVIII Congreso Nacional de Arqueología Argentina. La Rioja, Argentina.

"Rosenvasser, A. (1933, 11 de marzo). Breve Papiro del Museo de Historia Natural de Buenos Aires nos recuerda "las Aventuras de Sinuhe", La Nación, pp. 1.

» Rosenvasser, A. (1972a). Las piezas egipcias del Museo Etnográfico de Buenos Aires (Primera Parte). Revista del Instituto de Historia Antigua Oriental, 1, 4.

» Rosenvasser, A. (1972b). El papiro Buenos Aires Sinuhe B 251-6, en "Las piezas egipcias del Museo Etnográfico de Buenos Aires (Primera Parte), I." Revista del Instituto de Historia Antigua Oriental, 1, 5-12.

» Rosenvasser, A. (1972C). Las aventuras de Sinuhe: el pasaje B.251-7 y el papiro Buenos Aires (A propósito de H. Grapow, "Der stilistische Bau der Geschichte des Sinuhe, 1952"). Revista del Instituto de Historia Antigua Oriental, 1, 13-19.

"Rosenvasser, A. (1972d). El papiro funerario de Khonsu Thot (Frag. 2 y 3). Revista del Instituto de Historia Antigua Oriental, 1, 20-56.

"Santos, D. M. (2003). La colección egipcia del Museo Etnográfico de Buenos Aires. Ataúd de Amenirdis, primera parte. Aegyptus Antiqua, 11, 11-42.

"Santos, D. M. (2007). La colección egipcia del Museo Etnográfico de Buenos Aires. Ataúd de Amenirdis, segunda parte. Aegyptus Antiqua, 12, 12-49.

"Schorsch, D. (2007). The Manufacture of Metal Statuary: "Seeing the Workshops of the Temple". En M. Hill \& D. Schorsch (Eds.), Gifts for the gods: images from Egyptian temples (pp. 189-199). New York: The Metropolitan Museum of Art, New York.

»Trelles, M. R. (1856). Memoria presentada a la Asociación de Amigos de la Historia Natural del Plata, sobre el estado del Museo y demas relativo á la institución. Buenos Aires: Imprenta de "El Orden". 